\title{
Faculdade
}

de Ciências Econômicas UFRGS
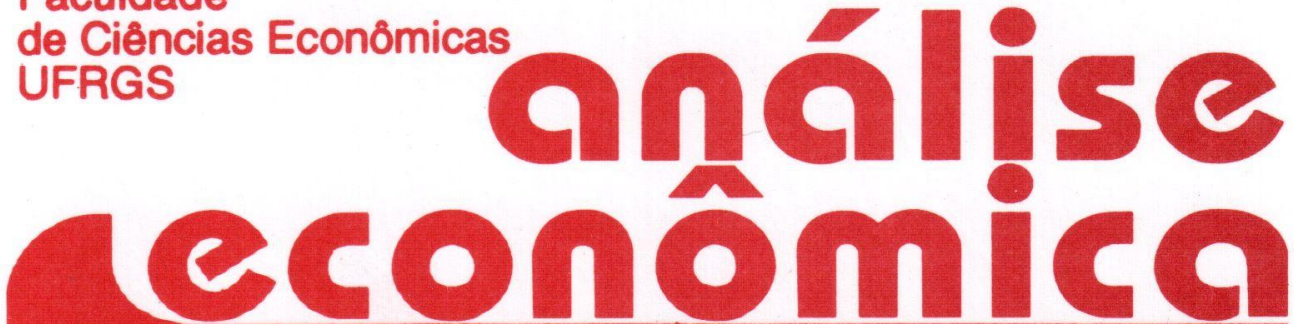

- HIPERINFLAÇÃo E A FORMA FUNCIONAL DA DEMANDA DE MOEDA Fernando de Holanda Barbosa

- AJUSTE Y REFORMA ESTRUCTURAL EN ARGENTINA, 1989/93 Gustavo Ferro

- MUdANÇAS NA ESTRUTURA do COMÉRCIO EXTERNO BRASILEIRO Álvaro Barrantes Hidalgo

- EQUILIBRIUM MODELS OF TRADE EQUATIONS: A CRITICAL REVIEW Marcelo S. Portugal

- THE THEORY OF FREE BANKING Anna J. Schwartz

- ARE BANKING CRISES A FREEMARKET PHENOMENON? George Selgin

- tamanho de estabelecimento AGRICOLA E PRODUTIVIDADE. Paulo D. Waquil

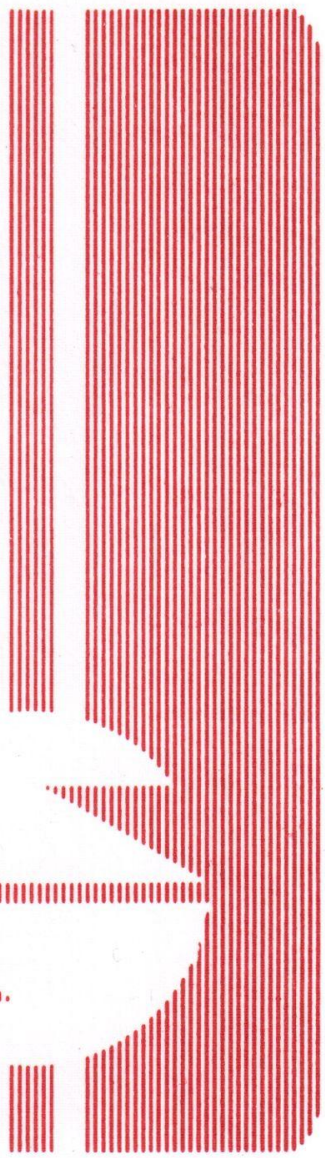


UNIVERSIDADE FEDERAL DO RIO GRANDE DO SUL

Reitor Prof Hélgio Henrique Casses Trindade

FACULDADE DE CIÊNCIAS ECONÓMICAS

Diretor. Prof Pedro Cézar Dutra Fonseca

CENTRO DE ESTUDOS E PEQUISAS ECONÔMICAS

Diretor: Prof. Roberto Pires Pacheco

DEPARTAMENTO DE CIÉNCIAS ECONÓMICAS

Chefe: Prof Fernando Ferrari Filho

CURSO DE PÓS-GRADUAÇÃO EM ECONOMIA

Coordenador: Prof. João Rogério Sanson

CURSO DE PÓS-GRADUAÇÃO EM ECONOMIA RURAL.

Coordenador. Prof. Juvir Luiz Mattuella

CONSELHO EDITORIAL: Achyles Barcelos da Costa, Aray Miguel Feldens, Atos Freitas Grawunder, Carlos Augusto Crusius, Fernando Ferrari Filho, João Rogério Sanson, Juvir Luiz Mattuella, Marcelo Savino Portugal, Maria Imilda da Costa e Silva, Nali de Jesus de Souza, Nuno R. L. de Figueiredo Pipto, Otília Beatriz K. Carrion, Paulo Alexandre Spohr, Pedro Cezar Dutra Fonseca, Roberto Camps Moraes, Valter José Stülp, David Garlow (Wharton Econometrics Forecasts Assoc, E. U.A.), Edgar Augusto Lanzer (UFSC), Eleutério F. S. Prado (USP), Fernando de Holanda Barbosa (FGV/RJ), Gustavo Franco (PUC/RJ), Joaquim Pinto de Andrade (UnB), Juan. H. Moldau (USP), Werner Baer (Univ de lllinois, E U A)

COMISSÃO EDITORIAL: Atos Freitas Grawunder, Pedro Cezar Dutra Fonseca, Marcelo Savino Portugal, Nali de Jesus de Souza.

EDITOR: Roberto Camps Moraes

SECRETARIA: Rosângela Ellwanger Soares (Secretária), Vanete Ricachescki (revisão de textos)

FUNDADOR: Prnf. Antônio Carlos Santos Rosa

Os materiais publicados na revista Análise Econômica são da exclusiva responsabilidade dos autores. É permitida a reprodução total ou parcial dos trabalhos, desde que seja citada a fonie. Aceita-se permuta com revistas congêneres. Aceitam-se, também, iivros para divulgação, elaboração de resenhas e recensões. Toda correspondência, material para publicação (vide normas na terceira capa), assinaturas e permutas devem ser dirigidos ao seguinte destinatário:

PROF. NALI DE JESUS DE SOUZA

Revista Análise Econômica

Av. João Pessoa, 52

CEP 90040-000 PORTO ALEGRE - RS, BRASIL

E-MAIL: NALI@VORTEX.UFRGS.BR

Telefones: (051) 316-3348 e 316-3440

Fax (051) 225-1067 


\section{AJUSTE Y REFORMA ESTRUCTURAL EN ARGENTINA, 1989/93*}

Gustavo Ferro*

\section{SINOPSIS}

Este trabajo aborda la question de la reciente hiperinflación argentina, resaltando las políticas macoeconómicas adoptadas por los diversos gobiernos para combatirla. Ello también elabora un retrospecto amplio de los principales eventos de política económica en la Argentina en el siglo 20 . Finalmente, el trabajo hace una crónica de las principales medidas y leyes relacionadas con el Plan de Convertibilidad y sus resultados hastá 1993.

\section{INTRODUCCIÓN}

Desde 1989 en que se produjera el primer episodio hiperinflacionario, la economía argentina ha sido sometita a um processo de ajuste y reforma estructural de dimensiones, y a una velocidad muy granda. Su economía mostraba signos de estancamiento por un periodo prolongado, y una muy alta inflación, originada en problemas fiscales crónicos. La falta de dinamismo del sector externo hacía que, en una economía sin crédito externo por casi una década, los resultados magros de la cuenta corrente alcanzaran en los años buenos a pagar la abultada deuda externa, contraida a fines de la década de los setenta y principio de los años ochenta, y destinada a financiar fuga de capitales y gasto en consumo principalmente.

El ajuste y la reforma estructural tuvo etapas diversas, produciéndose los mejores resultados a partir de abril de 1991, con la Ley de Covertibilidad Desde alli, se lograron índices aceptables y en descenso de inflación, creció vigorosamente el $\mathrm{PBI}$, la inversión y la actividad industrial, el empleo no decayó en forma relevante, a pesar del severo ajuste de las finanzas publicas, y el Estado pudo reducir en forma imporiante su endeudamiento y reprogramarlo, meciiante la venta de empresas de

\footnotetext{
* Este trabajo es parte de un proyecto de investigación financiado por una beca del CONICET (Consejo Nacional de Investigaciones Cientificas y Técnicas, de Argentina), titulado "Politicas para el desarrollo de mercados de capitales en un escenario porterior al logro de la estabilidad". La primera parte de él, trata del ajuste y la reforma estructural, con el caso argentino cumo aplicación especifica.

Economista argentino, ex-alumno del Curso de Pós-Graduação em Economia da UFRGS. Actualmente Becario de Investigación del CONICET, y docente de la Universidad Nacional de Rio Cuarto, Argentina
}

Cód. AEA 133
Palabras-clave: hiperinflación política cambiaria.

\section{ANÁLISE ECONÔMICA}

\section{ANO 11}

Setembro/93

p. 17-54 
su propiedad y la renegociación de la deuda a largo plazo con los bancos comerciales.

A continuación se analizará el processo de ajuste y reforma estructural, a dos años del Programa de Convertibilidad. Primeramente se hará una breve sinopisis histórica del desempeño pasado de la economia argentina, luego serán revistados los episodios hiperinflacionarios y los primeros pasos de la política económica en dirección a la estabilidad (años 1989 y 1990). A continuación se evaluarán los resultados de los años más recientes de la economia argentina y el Programa de Convertibilidad, mostrando sus grandes hitos de política económica, y los resultados al presente. El Anexo Estadístico a este capitulo exhibe las cifras de la economia argentina.

\section{BREVE SINOPSIS}

Argentina se independizó da España en 1816, pero se vió sumida en conflictos intestinos hasta 1860. A partir de la Organisación Nacional, la unificación del Interior y Buenos Aires y la ocupación territorial, comenzó el crecimiento económico fundado en la absorción de factores (trabajo inmigrante, inversión externa, y extensión de la frontera agroganadera), y la exportación de productos de la agricultura y la granaderia pampeanos hacia Europa. El último cuarto del Siglo XIX y los primeros años del Signo $X X$, fueran de un vigoroso crecimiento econúmico.

La Primera Guerra Mundial provocó una impasse en el crecimiento, a raiz de la interrupción del comercio con Europa, la detención del flujo migatório y la reversión de inversiones. En los años de la guerra el crecimiento del PBI fue lento y la inflación promedió los 9 puntos anuales (Cuadro 1- Anexo Estadístico). Hasta 1916 Argentina tuvo gobiernos conservadores. En aquella fecha fue electo Hipólito Yrigoyen, caudillo radical, que gobernó hasta 1922, siendo reemplazado por Marcelo T. De Alvear de su mismo partido (1922-28)

Los diez años de siguientes a la conflagración fueron de prosperidad y baja inflación. Argentina gozaba del privilegio de tener en 1929 la sexta renta anıal per cápita de mundo (Cuadro 2 - Anexo Estadístico) Yrigoyen volvió al poder en 1928. Perc !a Depresión de ios años 30 asetó un duro golpe a la econorria argentina. El producto cayó entre 1929 y 1934, para recuperarse el crecimiento desde ese año pero a tasas menores que en el período previo a la crisis

El grado de apertura de la economía disminuyó y la importancia de las exportaciones argentinas sobre el total mundial decreció sin pausa desde entonces (Cuadro 3 - Anexo Estadístico). En 1930 cayeron a la mitad los precios internacionales de los cereales y la lana, y se establecieron restricciones cuantitativas a las exportaciones de carne vacuna, que cayeron un $50 \%$. Desde aquella fecha a 1955 no hubo alternativas a la sustición de importaciones (Conesa, 1992). El presidente Yrigoyen fue derrocado en 1930. Desde 1932 a 1943 gobernaron los presidentes conservadores Justo, Ortiz y Castillo, que llegaron al poder mediante el fraude electoral. En 1943 tomaron el poder militares nacionalistas, que tras elecciones celebradas en 1945 ganadas por el General Perón, entregaron a este el poder, que ejercería hasta 1955, reforma constitucional y reelección mediante. 
Durante la Segunda Guerra Mundial, el PBI argentino creció a un ritmo cercano al $4 \%$ anual, conservando una inflación relativamente baja, pero en ascenso. El país acumuló acreencias contra el resto del mundo a raiz de la provisión de alimentos a los beligerantes y la virtual suspensión de importaciones industriales.

Entre 1945 y 1949, la economía creció a uria tasa anual ligeramente superior al $4 \%$ en promedio, pero la inflación trepó a cerca del $20 \%$ anual, cerrándose al comercio exterior de importación, con una politica deliberada de industrialización de sustitutos de importaciones, crecimiento de la participación del Estado en la economía y de las políticas sociales desde el gobierno. La lógica del modelo de sustitución de importaciones implicaba que la produción local gozara de alta protección; para contrarrestar la escasa dimensión del mercado, se procuraban altos salários ieales, que se conseguian mantiendo bajos los precios internos dos bienes agropecuarios de exportación, principales componentes de la canasta de consumo de los assalariados.

Sectores proveedores de bens y servicios públicos fueron nacionalizados. EI último grupo estaba compuesto por empresas de capitales extranjeros, muchas británicas. El Reino Unido al hacer inconvertible la libra en la postguerra, impuso un virtual bloqueo sobre los superávit argentinos acumulados durante el conflicto, y esos fondos fueran utilizados para nacionalizar empresas como los ferrocarriles y las telecomunicaciones.

El sector primario expurtador fue tributario del crecimiento de la industria y de los servicios mediante diversos instrumento de política económica, como tipos de cambio diferenciales y el control de cambio, la nacionalización del crédito y su uso selectivo hacia los sectores industriales y de servicios, etcétera. También se produjo una considerable migración de personas desde el campo hacia las ciudades. La participación de los salarios en el producto creció, avalada por las politicas públicas y el desarollo de los sindicatos.

La segunda fase del peronismo, desde 1949 hasta 1954 se caracterizó por la desaceleración del crecimiento económico, el aumento de la inflación y las crisis externa motivadas por la perdida rentabilidad de la actividade exportadora, por un lado, y la escassez de divisas para solventar importaciones requeridas por el sector doméstico productor de bienes no transables internacionalmente. Haciā 1954 se advirtió una mejor disposición al capital extranjero, cuando el gobierno estuvo a punto de concluir concesiones pará explotación de petróleo con empresas estadounidenses.

Perón fue derrocado en 1955 y tras un interinato militar, resultó elegido presidente Arturo Frondizi (desarrollista, escindido del radicalismo tradicional), mientras el peronismo era proscripto (lo sería hasta 1973). Entre 1955 y 1959 se creció a buen ritmo (casi $3 \%$ anual en promedio), pero la inflación se duplicó respecto del quinquenio anterior (Cuadro 1 - Anexo Estadístico). Los dos quinquenios siguientes tuvieron desempeños económicos aún mejores, con la inflación promediando el $20-23 \%$ anual. Frondizi profundizó la sustituición de importaciones abriéndose al capital extranjero. Progressaron bajo su gobierno las industrias metalmecánicas y petroquímicas

Frondizi fue derrocado en 1962, y en las elecciones de 1963 fue consagrado presidente Arturo Illia, radical. Gobernaria hasta 1966, cuando fue reemplazado tras 
un golpe militar, por el General Onganía. Bajo el gobierno Frondizi se había implementado um programa de estabilización para bajar la inflación de 1959 (cercana al $100 \%$ anual) a un muy bajo registro en 1960, bajo el ministerio de Alsogaray. Ongania tabién efectuó un plan de ajuste bajo el ministro de Krieger Vasena. Sin embargo, un clima de intranquilidad social motivó la caída del presidente y su reemplazo por otro militar, el General Levingston. La prosperidad económica no condecia con el clima social, abonado por la proscripción del peronismo desde 1955, que aún se manifestaba fuerza politica mayoritaria. El tercer general del período, Lanusse, que despaizó en 1971 a Levingston, llamó a elecciones sin proscripciones en 1973.

Entre 1970 y 1974 la economia creció más de un 5\% anual promedio,pero la inflación fue en creciendo, superando el $40 \%$ anual, el doble del quinquenio anterios. Las elecciones de 1973 fueron ganadas por el peronismo.

El gobierno de este partido comenzó con un plan de estabilización que pretendia "inflación cero", a la vez que una redistribuición del ingreso en favor de los asalariados. El ministro Gelbard aplicó políticas de controles de precios, expansión de salarios por decreto, control riguroso de cambios, elevación notoria del gasto público y ampliación de la nómina de empleados del Estado. El Plan Gelbard degeneró en 1975 una explosión de la inflación reprimida, con liberación de precios y devaluación del tipo de cambio. Antes el desabastecimiento de productos sometidos a controles era generalizado. La presión sindical determinó que la devaluación no fuera efectiva y los sindicatos reclamaron la recuperación salarial de los efectos del programa sucesor a Gelbard, denominacio "Rodrigazo"(por el ministro de economía Celestino Rodrigo en 1975). Perón habia muerto en 1974, dejando el poder a la vicepresidente, su esposa. El mal manejo económico, las disputas sucesorias y la creciente gravidad del enfrentamiento armado entre las fuerzas armadas y de seguridad contra las guerrillas urbana y rural que desde 1970 actuaban en Argentina, debilitaron al gobierno de Isabel Perón, que seria derrocad en marzo de 1976. Una buena caracterización del período peronista de 1973-76, tanto en sus aspectos económicos como políticos, efectúa Di Tella (1983).

El gobierno militar intentó estabilizar primeramente con políticas de ingresos, controlando los precios y mayormente los salarios, y la recucción del bache fiscal que en 1975 era de $14,5 \%$ del PBI (Ver Cuadro 4 - Anexo Estadistico). Se pretendió evitar la baja del gasto público, que descendió ties puntos del PBI en 1976 y 1977, pero volvió luego a los niveles de 1975 , a raiz de la potencial impopularidad de medidas de austeridad. El enfrentamiento con la guerrilla fue abierto

Las incoherencias de la política económica pretendidamente estabilizadora, pero expansiva, y retóricamente liberalizante, pero que aumentó la esfera de competencias y regulaciones del Estado, está muy bien tratada en Lücke y Pascual Spada (1986).

En 1978, ante el fracaso de la política de estabilización gradualista en disminuir la inflación, se apeló a nuevos instrumentos: a la vez que se pautaba un ritmo descendente y conocido de devaluación de la moneda local, se abria la economia para disciplinar los precios del sectcr de biens trasables internacionalmente. Los déficit públicos siguieron siendo de dimensión cercana al $7 \%$ del $\mathrm{PBI}$, consolidando el del Sector Público no Financiero y el del Banco Central de la Renública 
Argentina- BCRA (déficit cuasifiscal). Fueron excepciones los años 1977 y 1980 . En 1977 se terminó el sistema de nacionalización de depósitos en el sistema financiero (encaje del $100 \%$ que regió en los períodos de gobierno peronista), liberando las tasas de interés y permitiendo la creación secundária de dinero al permitirse un encaje fraccionario sobre las imposiciones. EL Estado se hacia garante de los depósitos en las instituiciones financieras. El experimento terminó con quiebras y el Estado pagando las cuentas de la irresponsabilidad o falta de escrúpulos de muchos bancos.Las pérdidas del Estado por garantizar depósitos de bancos quebrados se calcularon en su momento en más de U\$S 8.600 millones entre 1980 y 1986 (Casas, 1991)

El esquema de la Cuenta de Regulación Monetaria, mecanismo de compensación entre cargos cobrados por el BCRA a los bancos sobre encajes constituidos a partir de los depósitos en cuenta corrente, y remuneración de reservas sobre imposiciones a interés, aumentó el déficit cauasifiscal (pérdidas del BCRA) a partir de que la aceleración de la inflación, aunada al acortamiento legal de los prazos de los depósitos a interés, mientras se desplazaban depósitos a la vista hacia el segmento a interés. En 1985 sería cambiado régimen de la Cuenta de Regulación Monetaria, ya no monentizándose el déficit causifiscal devengado, sino transformándolo en depósitos indisponibles (remunerados) de los bancos en el BCRA. Muy buenos tratamientos de la cuestión del déficit cuasifiscal del BCRA se encuentran en FIEL (1990) y Artana et al (1991)

El programa estabilizador del ministro Martinez de Hoz no logró controlar la inflación, y la combinación de politicas expansivas, inflación doméstica mayor a la tasa pautada de devaluación indujo una crisis en el sector real de la economía. EI posterior presidente militar, Viola, que sucedió a Videla (1976-81), devaluć la moneda. A fines de 1981 fue sucedido por Galtieri, presidente que inició la gestión económica con un programa liberalizante truncado por la Guerra de las Malvinas (abril - junio de 1982). La derrota militar precipitó la caída del presidente, su reemplaza por Bignone, el llamado a elecciones, y en el terreno económico, una vuelta atrás a la apertura económica, y la nacionalización de la deuda exierna privada. En agosto de 1982 la declaración de insolvencia de México había precipitado lo que se conoceria como la Crisis de la Deuda.

Entre 1975 y 1990 , la Argentina tuvo un período de notorio estancamiento. Entre 1974 y 1990 el PBI prácticamente no varió, en tanto la población pasaba de 25 a 32 milliones, retrocediendo en consecuencia el PBI per cápita en un $22 \%$

En el mismo período, el PBI de los PD y los de América Latina crecieron un $50 \%$ aproximadamente, duplicandóse el de Japón. Yendo al Cuadro 1 (Anexo Estadístico), se advierte que entre 1975 y 1979 , el PBI promedió un incremento anual de $1,53 \%$ y la inflación un $223 \%$, entre 1980 y 1984 el primero dencendió a una tasa promedio del $1,08 \%$ y la inflación se mantuvo en 274 pontos anuales promedio. El producto habría de descender un 1\% anual entre 1985 y 1989 , y la inflación se mantuvo en 274 puntos anuales en promedio. El producto habría de descender un $1 \%$ anual entre 1985 y 1989 , y la inflación crecer desde $81 \%$ de 1986 , conseguida merced a un programa estabilizador heterodoxo, a la primera hiperinflación de 1989. Desde 1990, el PBI ha retomado el crecimiento, casi nulo en ese año, a tasas mayores al $8 \%$ anual en el bieno siguiente. 
La deuda pública externa argentina creció de U\$S 4.000 milliones en marzo de 1976 a U\$S 17.170 milliones en marzo de 1981 . En diciembre de 1983 era de U\$S 45.000 milliones. Entre 1976 y 1983, la deuda se contrajo en princípio para financiar inversiones de empresas públicas; posteriormente para financiar fugas de capitales. En 1978 la deuda ascendia a 12.496 milliones, llegando a U\$S 43.634 milliones en 1982. En 1978 el stock de capital fugado ascendia a U\$S 2.000 milliones. A fines de 1981, era de 20.000 milliones (el más alto registro entre 1978 y 1989). Durante los años ochenta este último se mantuvo cercano a los U\$S 18.000 milliones, en tanto el stock de deuda pública externa crecia hasta sobrepasar los U\$S 60.000 milliones (Conesa, 1992).

El Banco Mundial (Economic Memorandum on Argentina, Report 4979-AR, 22/06/1984, p. 18) estimó que la diferencia de endeudamiento entre 1982 y 1978 se explica por U\$S 19.000 milliones de fuga de capitales y U\$S 10.000 milliones de importaciones no registradas de equipos militares. En el mismo periodo, se pagaron US $\$ 13.000$ milliones de intereses y se elevaron las reservas internacionales en U\$S 2.500 milliones (Casas, 1991).

La deuda externa privada fue nacionalizada en 1982. El Estado se hizo cargo de las deudas de las empresas en moneda extranjera, cambiándolas por deuda en moneda doméstica de las empresas al BCRA Esta fue licuada mediante el expediente de acelerar la inflación, que erosionó el valor en pesos de las acreencias del organismo monetario. Quien llevó adelante esta política, fue el presidente del BCRA Domingo Cavallo, aue estuvo al frente de ese organismo solamente un par de meses en 1982. Anteriormente, el Estado había otorgado seguros de cambio a muchos deudores privados externos y devaluado fuertemente la moneda durante el ministerio Sigaut (1981). Las elecciones de 1983 fueron ganadas por el candidato radical Raul Alfonsin, quien asumió en diciembre de ese año. Primeramente intentó una reativación de la economía con políticas expansivas de demanda. Pero la inflación se aceleró llegando a totalizar casi un $700 \%$ en 1984 , bajo el ministerio de Grinspun. En 1985 aquella amenazaba convertise en hiperinflación. En junio, el nuevo ministro de la ecoriomia Juan Sorrouille, lanzó un programa económico que perseguia la eiiminación de la inflación con una combinación de politicas de ingressos, anuncios para actuar sobre las expectativa, desindexación de la economía, y una reforma monetaria. La eliminación del déficit fiscal se pretendía conseguirla en forma casi indolora, mereced a la reversión del efecto Oliveira-Tanzi en la recaudación tributaria con la desaceleración inflacionária, el aumento y congelamiento de tarifas por bienes y servicios públicos, salários del sector público congelados, y el "desagio" (quita de la prevención por inflación esperada a los contratos) de las deudas públicas con proveedores. Los precios del sector privado fueron congelados, lo mismo ocurrió en el salario y el dólar, ya que el tipo de cambio libre lideraba los procesos indexatorios. El plan logró detener la inflación, proporcionar en 1986 un crecimiento del IPC de "sólo" un $81 \%$ y aún más notorio un $7,3 \%$ de elevación en el PBI tras el traspié del $6,6 \%$ negativo en 1985 (Cuador 1- Anexo Estadístico). En tal sentido, la estabilización no tuvo elevados custos en desempleo y producción perdidos. El partido del presidente Alfonsín logró una buena elección legislativa a fines de 1985. Sin embargo las politicas de ingreso que determinaron el éxito inicial, precipitaron la caída posterior. 
Los resultados del Plan fueron erosionandose ante la no aplicación de políticas de gestión de la demanda, en tanto los servicios de la deuda extena pesaban sobre el presupuesto oficial y caían en 1986 los precios de productos primarios exportables. El congelamiento fue progressivamente abandonado en 1986 y el tipo de cambio fijo abandonado, reemplazándolo por un crawling peg pasivo. En 1987 desacelerado el crecimiento de 1986 y duplicado su registro de inflación, el partido gobernante sufrió una derrota aplastante en el tercer trimestre de 1987. Espejo Ortega (1989) brinda un interesante estudio del Plan Austral, como se lo conoció por el nombre del nuevo signo monetario que introdujo (reforma monetaria "cosmética").

El año 1988 fue de caída del producto y de aceleración de la inflación. Algunos intentos de privatizar empresas públicas no progresaron en le Congreso. Ante la proximidad de la renovación presidencial, estando la inflación en crecimiento, se intentó un nuevo intento estabilizador en agosto de 1988, conocido como Plan Primavera Consistía en la defensa del BCRA de uma paridad para el dólar, y políticas aisladas de ingreso. En Plan debía permitir al gobierno llegar a las elecciones de mayo de 1989 con indices mensuales de inflación de "un dígito" Pero el esquema resultó fallido La expansión monetaria daba combustión a la demanda de dólares, mientras que las reser azs de intervención del BCRA eran limitadas. En segundo lugar, activó aquella demanda el temor a la victoria del candidato peronista Carlos Menem, con un programa vago de gobierno y un discurso populista.

\section{HIPERINFLACIÓN Y ESTAB!'IDAD (1989-90)}

La presión sobre las reservas del BCRA erosionaron las reservas de éste y se precipitó, con la suba del dólar, la hiperinflación, en tanto proseguia la campaña electoral. El Cuadro 5 (Anexo Estadístico), muestra la evolución de la cotización del dólar entre 1988 y 1990.

El Cuadro 6 (Anexo Estadístico), muestra la evolución de la inflación durante el primer episodio hiperinflacionario, entre abril y agosto de 1989 . Cotéjense la evolución de los precios y la tasa de devaluación a partir de la evolución del dólar "paráíclo". En tanio, el mercado de cambios "comercial" regía para el comercio exterior. Fueron vanos todos los intentos de contener la huida del dinero doméstico y las explosión dos precios. Las elecciones presidenciales del 14 de mayo de 1989 fueron ganadas por el candidato opositor Carlos Menem, por holgada mayoria sobre el oficialista Eduardo Angeloz. La hiperinflación se aceloró en junio y llegó a un pico en julio del $196 \%$ mensual. El presidente saliente Alfonsín concluía su mandato el 10 de diciembre. Junto con el vice presidente, renunciaron a principios de julio, transpasando el poder al presidente electo el 8 de julio de 1989. Este, dias antes habia ofrecido el ministerio da economia a un ejecutivo del grupo económico Bunge y Born, pronunciando en ocasión de su ascenso al poder un discurso modernizador y libreempresista, que contribuyó a tranquilizar las expectativas. El ministro da economia designado murió a poco de asumir, siendo reemplazado por otro ejecutivo de su grupo empresario, Néstor Rapanelli.

El dólar fue anclado a A $650(\$ 0,065)$. La tasa de inflación bajo bruscamente a $38 \%$ en agosto, $9 \%$ en septiembre y $6 \%$ en octubre y noviembre. Dos instrumentos 
legales fueron utilizados por el gobierno nacional: La Ley de Emergencia Económica y la Lei de Reforma del Estado de octubre de 1989.

Se abría el camino a la eliminación de subsidios, equiparación de derechos al inversor local y al extranjero, diferimiento de deudas del Estado y privatizaciones Las leyes 23.696 (Emergencia Económica) y 23.697(Reforma del Estado), fueron los marcos normativos para le reforma estructural (Rojo y Canosa, 1992). La declaración de emergencia implicó que el Congreso delegaria facultades en el Poder Ejecutivo de los que éste haria uso posteriormente

Pero el presidente del Banco Central prefería esterilizar el crecimiento monetario con mayores encajes remunerados y depósitos indisponibles, aumentando el déficit causifiscal. El Indice de Produción Industrial de la Fundación Mediterránea mejoró de un nivel de 87 en junio, a 97 en noviembre.

Respecto a las deudas del Estado, tenian varias vertentes

- Deudas internas documentadas, mediante títulos estatales con diversas claúsulas de ajuste.

- Deuda del Banco Central, por remuneración de encajes a los bancos comerciales. Para evitar el efecto de la expansión monetaria, el déficit causifiscal devengado de ese origen se mantenía en forma de "depósitos indisponibles" en le BCRA.

- Deudas diversas sin documentar, con proveedores del Estado, clase pasiva, por liquidaciones debajo del monto legal, con provincias por regalias petroleras, etc.

- Deuda externa nacionaliza

En diciembre de 1989, el ministro Rapanelli consolidó efimeramente el primer grupo de deudas, por medio de un bono que trocó compulsivamente a diez años los diversos títulos federales en circulación en moneda local. La consolidación compulsiva de la deuda precipitó una crisis de confianza, el descrédito del equipo económico y el cambio de ministro de económia y presidente del BCRA.

El nuevo ministro González liberó precios y tipo de cambio y procedió al canje compulsivo del segundo grupo de deudas, cesando el déficit cuasifiscal de ese origen. Los encajes remunerados y indisponibles fueron eliminados, y su monto canjeados por un complejo de títulos públicos, de los cuales el más notorio el Bonex 1989, de diez años a su maduración, Ėmitido en dólares, con tres años de gracia y favorecido for claúsula de extraterritorialidade La contrapartida fue permitirle a los bancos devolver sus depósitos a interés en Bonex 89, que cotizaron inicialmente a un $13 \%$ de su valor nominal El monto de la confiscación ascendió a U\$S 1.800 millones. El dólar pasó de A 723 a fin de octubre a A 1.950 a fin de año. La hiperinflación volvió a precipitarse y solamente la escassez de dinero doméstico mitigó en marzo lo que habia sido hasta ese momento una corrida ininterrumpida al dólar. El dólar costó hasta A 5.850 en febrero de 1990. A fin de ese mes se detuvieron las compras de dólar de las empresas, y en marzo e! BCRA reclamó a los bancos la devolución de redescuentos. El dólar bajó desde A 5.850 a A 4.650. En abril de 1990 la hiperinflación cesó. El IPC creció ese mes un 11,4\%, comenzó la remonetización, cresciendo la base monetaria un $32,2 \%$ y el dólar pasaba a costar A 4.980, manteniéndose por 7 meses. A fin de febrero de 1990 la base monetaria valia U\$S 980 millones, contra U\$S 1.782 en agosto y U\$S 4.144 milliones en nc:iembre. El Cuadro 7 (Anexo Estadistico), muestra la evolución de las variables 
durante la hiperinflación de 1990. Un buen tratamiento de los episodios hiperinflacionarios se brinda en Graziano (1991). Las altas tasas de interés reales, dado el bajo nivel de monetización, y el tipo de cambio aunque fluctuante, estancado, motivaron ingreso de capitales y apreciación de la moneda local durante 1990.

El BCRA se aprovisionó de reservas, que de U\$S 442 millones en febrero de 1990 , pasaron a US\$ 3.242 en diciembre. El superávit de balanza de pagos fue de U\$S 1.750 millones, por primera vez en muchos años revirtió la fuga de capitales.

La balanza comercial fue superavitaria en la cifra récord de 8.000 millones de dólares, resultante del alto tipo real de cambio en 1989 (declinante en 1990), y del bajo nível de actividad doméstico.

En 1989 se habian producido privatizaciones de los canales de televisiones estatales 11 y 13 de Buenos Aires. En 1990 se procedió la venta de la empresa estatal de teléfonos ENTEL, dividida en dos partes. La zona norte adquirida por el consorcio STET-France Telecom y la zona sur fue comprada por Telefónica de España. La privatización, que dejó además el 35\% de las acciones en manos estatales (vendidas en 1991 y 1992) y un 10\% para ser repartida entre el personal, reportó U\$S 214 millones en efectivo, U\$S 380 millones a plazo y U\$S 5.000 millones de títulos de deuda externa a su valor nominal. Asimismo se vendió la empresa estatal de aviación Aerolineas Argentinas a un consorcio encabezado por Iberia en U\$S 130 millones en efectivo, U\$S 142 millones en Bonex 89 a su valor nomirial y U\$S 1.610 millones en título de la dueda externa a su valor nominal. Esta empresa fue parcialmente reestatizada en el período posterior, llegando en abril de 1993 la participación del Estado al 43\% del total, aunque el manejo continuá en manos de lberia

La actividad petrolera fue desregulada a partir de 01-01-91, abriendo el camino primeramente para la venta de los activos y despućs de la propia empresa estatal de petróleo YPF, convertida en sociedad anónina que se anuncia para medianos de 1993. También a partir de aquella fecha se efectuó una reforma arancelaria, de noca vida, que estabeleció un arancel uniforme del $22 \%$, más derechos especificos a sectores "sensibles" como automóviles, electrónicos de consumo y rodamientos El posterior ministro de economia, Cavallo, asumido a fienes de enero, reemplazaría este esquema por uno escalonado. de acuerdo al grado de elaboración de los productos que hahría de tener sucesivos retoques.

A principios de diciembre de 1990 el dólar cotizaba a A 5.100 , devaluándose en enero de 1991. El nuevo ministro Cavallo estableció una banda de flotación de entre A 8.000 ; A 10.000 . Hasta ese momento se habia preferido mantener en forma reservada los márgens de intervención del BCRA, con la idea de controlar el ingreso excesivo de capitales golondrinas. Durante febrero el dólar costaba A 9.400. La inflación se aceleró, pasando del $7,7 \%$ mensual en enero al $27 \%$ en febrero, $11 \%$ en marzo y $5,5 \%$ en abril. El nuevo ministro introdujo dos nuevos impuestos para cerrar el bache fiscal: el Impuesto a los Activos, gravando con el $2 \%$ anual los activos productivos, y el Impuestos a los Débitos Bancarios, del 1,2\% por operación, eliminado en julio de 1992. 


\section{EL SECTOR REAL DE LA ECONOMIA}

El Cuadro 9 (Anexo Estadístico), muestra la evolución del PBI año por año, desde 1980 hasta 1992, según las más recientes estimaciones del BCRA, de principios de 1993. El PBI en 1992 alcanzó los 226.000 millones de pesos, equivalentes a esa misma cifra en dólares dada la paridad actual (abril de 1993), vigente desde el Plan de Convertibilidad. Se advierte que en 1991 se volvió al nivel del PBI de 1980, sobrepasándolo recién en 1992. Sólo que la población de menos de 28 millones pasó a más de 33 . Las tasas de crecimiento son decepcionantes, con grandes caídas en 1981, 1982, 1985 y 1989, alzas importantes en sólo tres años, 1986, 1991 y 1992

La Inversión Bruta Interna (IBI) tuvo un comportamiento aún peor. Sus fluctuaciones, como se comprueba en el Cuadro 10 (Anexo Estadístico), fueron de muy grande magnitud. A pesar de las espectaculares recuperaciones de 1991 y 1992 , se halla aún $20 \%$ más baja que en 1980 , cuando en pesos de 1992 superó los 47.000 millones para nunca más llegar a aquel registro.

Las obligaciones emanadas de los intereses de la deuda externa significan un drenaje del $10 \%$ de la IBI por año (nível de 1992).

El Cuadro 11 (Anexo Estadístico), muestra la preocupante caída en la participación en el PBI de la IBI. De más del $25 \%$ del PBI, llegó a niveles mínimos del $14 \%$ en 1990. Los aumentos acumulados de 1991 y 1992 la han llevado a $16,7 \%$ del PBI, aún menor a la participación que ostentaba en 1988, antes de la hiperinflación

El PBI de 1992, \$226.637 millones se compone de $\$ 192.261$ millones de consumo, público y privado, $\$ 37.854$ de IBI, y un déficit de cuenta corriente de $\$$ 3.479 millones. Con expotación de bienes y servicios por $\$ 14.953$ milliones, el país importó por $\$ 18.432$ (bienes y servicios). La oferta global, igual a la demanda global, ascendió a $\$ 245.069$ milliones.

Junto con el $\mathrm{PBI}$, la produción industrial se ha recuperado vigorosamente desde la estabilización que indujo el Programa de Convertibilidad. El Cuadro 12 (Anexo Estadistico), da cuenta de la evolución de la producción industrial en los últimos años. Una perspectiva del sector a lo largo de la década de los ochenta y lo que va los noventa, la brincia el Cuadro 13 (Anexo Estadístico), con datos de evolución del índice de producción industrial que elabora FIEL.

La composición sectorial de! PBI que surge de las estimaciones más recientes que realiza el BCRA, muestram un descenso relativo de participación de los sectores productores de mercancías, respecto de aquellos que producen servicios (Cuadro 14- Anexo Estadístico)

Las tasas de desocupación y subocupación sumadas muestran que el $15 \%$ aproximado de la Población Económicamente Activa (PEA) tiene problemas de empleo, estando el $7 \%$ de esta desempleado (793.000 personaś) y el $8,1 \%$ subempleado ( 917.000 personas) según las estimaciones más recientes que se disponen (Cuadros 15 y 16 - Anexo Estadistico). Se observa en las mismas estadisticas, que ambas cayeron tras los nivels máximos alcanzados en los años hiperinflacionários, tras la estabilización. Inclusive los registros totales son menores que en abril de 1988, un año antes de producirse la hiperinflación. El ajuste y la 
reforma estructurales no parecen haber incrementado sustancialmente el desempleo, pese a las bajas de personal del Estado.

El sector público ha sido equilibrado en 1992, y se esperase comporte asi en el futuro. Las dudas provienen de estimaciones privadas que muestran un alto nivel de gasto público consolidado para 1993, posiblemente originado en las elecciones parlamentarias de octubre. De un déficit de más de 6000 millones de dólares en 1988 , se ha conseguido equilibrar el presupuesto nacional. La recaudación impositiva, basada en el IVA provee al presupuesto nacional. De este se han eliminado subsidios y se mantienen a un nivel controlable las erogaciones originadas en la deuda pública (Ver Cuadros 17 a 23 - Anexo Estadistico).

El sector externo de la economía de un grado de apertura creciente, ensayada bajo el ministerio de Martinez de Hoz (1976-81), pasó a ser muy cerrada desde 1982. El resultado de la cuenta mercancias fue superavitario desde ese año. Las importaciones se contrajeron en forma importante. Desde 1991, sumada la estabilización, la vuelta al crecimento y la apertura de la economia al relativamente bajo tipo de cambio real, el signo de la balanza comercial se ha revetido, y ha sido fuertemente deficitário en 1992 (Ver Cuadro 28 - Anexo Estadístico), sin embargo la balanza de pagos ha sido positiva merced al fuerte ingreso de capitales, priveniente de repatriación y privatizaciones principalmente (Ver Cuadro 19 - Anexo Estadístico)

\section{EL PROGRAMA DE CONVERTIBILIDAD DE ABRIL DE 1991}

A comienzos de marzo de 1991 se produjo una corrida cambiaria, abortada por la resistencia del BCRA ante la venta de dólares al tipo vendedor estabelecido de A 10.000 .

La Ley 23.928 de Convertibilidad y modificación de los articulos 617 y 623 de Código Civil de dictó el 27-03-91 Fijó el tipo de cambio convertible al dólar a A 10.000 vendedor desco el 01-04-91. El BCRA se comprometió a la defensa de ese tipo de cambio. Sus reservas deben equilivaler a por lo menos $100 \%$ de la base monetaria Se prohibió toda forma de indexación desde el 01-04-S1, volviendo al nominalismo en los contratos. $Y$ se pormitió utilizar cualquier moneda en transacciones y obligaciones, creando un verdadero sistema bimonetario, que de hecho existia por adopción de los agentes económicos del dólar con la excepión de pago de salarios y impuestos.

La economia se estabilizó, los índices de inflación mostraron tasas de crecimiento cada vez menores (Ver Cuadros 33 y 34 - Anexo Estadístico). La estabilidad cambiaria perdura (Ver Cuadro 8 - Anexo Estadístico). El mecanismo previsto en la convertibilidad, de defensa de la paridad fija del tipo de cambio, ha motivado que el mecanismo de remonetización fueran las compras de dólar del BCRA, cada vez que en el circuito mayorista este llegaba a 9900 (luego $\$ 0,99$ y más recientemente $\$ 0,998$ ). En marzo de 1991 , la base monetaria eran 4800 millones de dólares, superando los 11.700 en abril de 1993. El M2 que en marzo de 1992 apenas superaba los 7.500 millones de dólares, llegaba a 23.100 en abril de 1993. 
EI BCRA compró más de 9700 millones de dólares desde el 1 de abril de 1991. El respaldo en divisas de la base monetaria nunca cayó por debajo del $100 \%$. Las tasas de interés pasivas bajaron sustancialmente para los ahorristas, las activas aún son altas. Los depósitos en dólares en el sistema financiero pasaron de unos 3.400 millones en abril de 1991 a más de 12.700 dos años después. La capacidad prestable del sistema financiero, aún baja términos de PBI, se ha cuadruplicado, sumando pesos y dólares. Los Cuadros 35 a 40 del Anexo Estadistico, muestran el comportamiento de las variables citadas.

\subsection{Macropoliticas del programa de ajuste vigente}

Sintéticamente, el estado actual del Plan se caracteriza por lo que a continuácion se expone:

- La Ley de Convertibilidad ha determinado la eliminación de la política cambiaria como instrumento; la solución al problema de competitividad se procura obtenerla por el lado real (descenso de la inflación y crecimiento acelerado de la productividad).

- Ha significado estabelecer un tope estricto al crédito interno, una política monetaria passiva, ligada a la conservación del tipo de cambio fijo y la amplia sustitutibilidad entre peso y dólar.

- Se ha efectuado la apertura de la cuenta capital, y se observa una creciente apertura de la cuenta corriente (respecto a los niveles previos al ajuste, oscilante durante éste). Existen dudas en cuanto a la rentabilidad de los sectores exportadores y sustitutos de importaciones como resultado del set vigente de precios relativos.

Continúa el processo de integración económica con el Mercosur (Brasil, Uruguay y Paraguay), paises con los que rigen importantes rebajas arancelarias. - La política fiscal persigue uii presupuesto equilibrado, por control de gastos y crecimiento de la recaudación tributária. Contináun pendientes la renegociación de las relaciones fiscales Nación-Provincias y la reforma deı sistema previsıonal.

Las politicas monetarias y fiscales vicentes, implican la renuncia al impuesto inflacionario. Se ha logrado el aumentode la recaudación mediante:"

- concentración en un pequeño grupo de impuestos (fueron eliminados 20 impuestos desde la puesta en vigencia del programa, y la recaudación ha experimentado un gran crecimiento);

- acotamineto de la evasión por mayor control,

- crecimiento de la base imponible, manteniendo un nivel de actividad en ascenso.

Como problemas, en torno a la política fiscal

- eficiencia del gasto;

- evasión aún alta;

- sistemas fiscales provinciales;

- sistema tributario federal procíclico;

- equidad del sistema tributario federal.

- Deuda pública: 
- Se conseguió eliminar en la primera fase del ajuste el problema flujo del déficit cuasifiscal del BCRA y documentar el stock a largo plazo (Bonex 89, BIC, BOCE)

- Se documentó la deuda estatal pendiente, básicamente en el sistema previsional y con los proveedores del Estado;

- Ha habido una cancelación neta de deuda, al no efectuarse nuevas emisiones en reemplazo de los títulos que iban feneciendo;

- Parte importante de la deuda pública externa se recompró con el mecanismo de capitalización en la privatización de empresas públicas;

- Se ha acordado un esquema de renegociación de la deuda comercial mediante Plan Brady con bancos acreedores externos, que implicó quita del principal, garantía de su recompra a 30 años (fondeada don un Acuerdo Ampliado del FMI), y fijación de un tope a los interesses pendientes del grueso de la deuda.

- Se ha producido una caída del riesgo país y la reanundación del crédito externo. Las empresas principales del sector privado toman crédito barato en el exterior y cancelan crédito caro en el país, aumentando la oferta de financiamento a empresas medianas y pequeñas que no acceden al crédito externo.

- Reforma estructurales

1) Privatizatización de empresas públicas: lo recaudado disminuyó las deudas del Estado. Las mayores inversiones privadas revierten la caída del rubro, antes" situado en inversión pública. El costo de los servicios es soportado por los usuarios, terminando subsídios estatales para suplir pérdidas de empresas, que encubrían transferencias de ingresos a usuarios, proveedores o personal Las empresas privatizadas ingresan a las arcas estatales impuestos por sus utilidades. Como principal problema, puede citarse la demora en la consitución de entes regulatorios. Los Cuadros 24 y 25 (Anexo Estadistico), muestram el listado de empresas privatizadas en 1991 y 1992, y las metas para 1993.

2) Desregulación se procedió a desregular una serie de actividade para bajar costos internos y mejorar la competividad de la economia sin devaluar Los resultados fueron parciales En muchos casos las medidas dependian de politicas adicionales desde las provincias

3) Reforma previsonal: en trámite, prevé el paso a un sistema de capitalización y a la progresiva desaparición del sistema actual de iaparto que irisume ingentes recursos y presta pobres servicios. La reforma requiere elevar los ahorros las familias, parte de los cuales engrosarán los fondos prestables del mercado de capitales. Se ha sugerido para mitigar el efecto impacto, que las futuras administradoras de fondos de pensión y jubilacón (AFPJ) adquieran titulos públicos en un gran porcentaje de su operativa, a fin no recargar la presión fiscal sobre el sector privado. Fracasó el intento del gobierno de crear un nuevo impuesto al valor agregado no salarial (IEFE - Impuesto al Excedente Productivo de las Empresas) en 1991, para financiar el sistema de reparto, e ingresar al decapitalización de fondos provenientes de los impuestos al salario. El proyecto enfrenta resistencia gremial y de la oposición política.

4) Flexibilización laboral: la ley de empleo, de reciente sanción, introdujo modadlidades de contatación flexibles y un seguro desempleo para quienes perdieran el empleo después de la sanción de la ley y no fueran indemnizados. Se prevé elevar la flexihilidad del mercado laboral. Los empleados del Estados que 
gozaban de estabilidad laboral fueron reducidos mediantes acuerdos de retiros voluntarios o despidos, con indernnizaciones provenientes de préstamos de organismos multilaterales. A mayo de 1993 hay borradores de proyectos oficiales para renovar la legislación laboral en forma integral.

- Mercado de capitales se prevé su dinamización con el nuevo sistema previsional.

Respecto del sistema bancário, con una aún relativamente desmonetizada economia, hay capacidad prestable relativamente escasa y la banca debe disminuir costos fijos que implican una divergencia notoria entre tasas activas y pasivas Las primeras irán bajando a medida que la oferta de crédito crezca y permita diluir los costos fijos de la intermediación financiera La vuelta del crédito externo posibilita ello, complementando la lenta monetización de la economia.

Por otro lado, la banca oficial ha efectuado un intenso ajuste. A nivel nacional, persiste como agente financiero del gobierno federal el centenario Banco de la Nación Argentina. El Banco Nacional de Desarollo fue liquidado, el Banco Hipotecario Nacional fue convertido en entidad mayorista y la Caja Nacional de Ahorro y Seguro será privatizada. Un banco estatal de segundo piso, para financiar la expansión de las inversiones y exportaciones, el Banco de Inversión y Comércio Exterior, ha sido creado, pero su destino es ser privatizado.

La banca provincial, antes verdaderas ventanillas coparticipadoras del impuesto inflacionário a los gobiernos provinciales, ya que estos se sobregiraban con cargo a IBCRA, y éstes terminaba condonando los redescuentos, debieron dejar de cumplir ese papel. Varias entidades fueron privatizadas, todas efeciuaron grandes ajuste para disminuir sus costos. La cartera irregular se concentra principalmente en ellas, en menor medida en la banca nacional y, mucho menos, en la banca privada

El gobierno intentó encorsetar la tasa de interés activa, no habiéndolo logrado al presente

EI BCRA fue independizado por ley del poder politico, pero aún no fue efectuado el nombriamento de sus autoridades a término y con acuerdo del Senado como estabelece la norma

Aquiel ha suprimido los redescuentos y las operaciones de pase para la regulación de la liquidez, contra garantia de títuios públicos. Se "!mita a defenrler el tipo de cambio la banda caribiaria inicial de $\$ 0,99-\$ 1$, fue cambiada recientemente por $\$ 0,998-\$ 1$, lo que disminuye los costos de entrar y salir del dólar.

Las últimas reformas de fines de enero, permitieron:

- eliminar los plazos de las imposiciones a menos de 30 dias.

- bajar el encaje promedio, elevando la capacidad prestable, al nivel deseado por el mercado que pudo optar entre colocaciones más líquidas, con mayores encajes, o menos liquidas, sin encaje legal, prefiriendo direccionar excedentes hacía éstas.

- uniformar las reservas requeridas en depósitos en dólares y pesos en un $40 \%$ para cuentas corrientes y cajas de ahorro y $0 \%$ para depósitos a plazo fijo.

- permitir operar los depósitos a la vista en dólares como cuentas corrientes redimibles por cheques. 
Se ha profundizado la operatoria en obligaciones negociables. Empresas de primeira línea y bancos para fondearse, son sus principales emisores. No tienen encaje legal.

La bolsa tuvo una bonanza inusitada entre mediados de 1991 y mediados de 1992. Las cotizaciones tuvieron una explosión y la operatoria diaria pasó de un promedio de menos de 2 millones de dólares a un máximo de 100. El Estado aprovechó esa situación para colocar a muy buen precio las acciones remanentes de las empresas telefónicas privatizadas. Algunas emisiones privadas se realizaron. Ninguna de las colocaciones cambió la modalidad de la bolsa argentina, donde salvo muy pocas empresas la operatoria bursátil es de grupos minoritarios, que sumados no acceden al control Los controlantes no suelen arriesgar su mayoria en la bolsa. Tampoco es común el pago de dividendos en afectivo.

Después de las colocaciones, la Bolsa soportó una caída persistente, a un nivel menor a la mitad del pico de mayo de 1992. La capitalización bursátil en abril de 1993 ronda los 17.500 millones de dólares (Véase Cuadro 41- Anexo Estadístico).

El mercado hasta fecha reciente estaba dividido entre la Bolsa de Valores, que concentraba el grueso de las operaciones en acciones, y el Mercado Abierto Electrónico (MAE), con la mayoría de las transacciones en títulos públicos y las acciones de las empresas telefónicas privatizadas. La Comisión Nacional de Valores (CNV) es el organismo rector de este segmento del mercado de capitales en la Argentina Impulsó la autorregulación del MAE, compuesto por los bancos comerciales Estos llegaron a un acuerdo con la Bolsa, que permitirá el acceso de la banca a su sociedad, al par que monopolizará ésta el nogocio de acciones. EI MAE, por su parte tendrá la exclusividad en la operatoria de títulos públicos.

De estos circulan distintas series de Bonex (Bonos Externos, series 84, 87, 89 la más numerosa, 92 totalmentes en poder del BCRA, en dólares), distintas series de BOTE (Bonos del Tesoro, series !, II y 10, en dólares), BIC 5 (Bonos de Inversión y Crecimiento, en poder de la banca, provenientes del rescate de encajes e indisponibles de diciembre de 1989, en pesos), BOCON (Bonos de Consolidación, en pesos y en dólares), y Bonos Brady (Par, Discount y FRB). Resta emitir una serie de BOCON y a la vez se prevé su rescate parcial.

Los inversores institucionaies (AFPJ, Compañias de Seguro, Fondos Comunes de Inversión), aún no han alcanzado desarollo. Se espera que ello ocurra a partir de la reforma previsional. Simultáneo al desarollo de las AFPJ lo será el mercado de seguros de vida a que darán origen La privatización de la Caja Nacional de Ahorro y Seguro es otro hito en el crecimento del seguro Los Fondos Comunes de Inversión, por otro lado, ostentan escasa capitalización (no llega a los 200 millones de dólares), que disminuyó pari passu a la caída de la Bolsa tras el "Big Bang" posiconvertibilidad

\subsection{Los hitos del plan de convestibilidad}

El Plan de Convertibilidad tuvo varias hitos, que fueron anuncios e implementación de medidas de política económica. Pueden citarse los siguientes, que después se comentarán, a excepción del impacto de la Ley 23.928 que ya hemos analizado: 
1) Ley de Convertibilidad 23.928 (abril 1991),

2) Decreto de Desregulación Económica 2284 del 31-10-91. 1992,

3) Anuncio de Medidas de Mediano Plazo (Teatro Cervantes, octubre 1992),

4) Medidas de cierre de la economía (28-10-92),

5) Anuncios de bimonetización tras corrida cambiaria (11-92)1993,

6) Profundización de la bimonetización (31-01-93),

7) Medidas anunciadas ante la Asamblea Legislativa (01-05-93)

\subsubsection{Decreto de desregulación económica 2284 del 31-10-91}

La estabilización habiá hecho converger la inflación mayorista doméstica a niveles internacionales entre abril y octubre de 1991 (ver Cuiadro 34- Anexo Económica); los bienes no transables, en cambio habian experimentado subas de precios muy superiores (recogidas en la evolución del IPC). El Decreto 2.284 pretendía disminuir sobrecostos y distorsiones a fin de disciplinar los precios de los bienes no transables como la apertura de la economia habia hecho con los transables. El tijo de cambio real mejoraria sin devaluar la moneda, y con ello aumentaria la competividad de la economia.

Las regulaciones preexistentes pueden clasificarse siguiendo a Rojo y Canosa (1992) en:

1) Control de la oferta y la exportación de productos primarios pampeanos (datando de la décad de los treinta)

2) Promoción de industrias básicas (provenientes de los años cincuenta y sesenta).

3) Limitación de la sobreoferta de productos primarios no pampeanos (años sesenta y setenta).

4) Regulación de la oferta de servicios professionales (proveniente de los años setenta)

5) Limitaciones al comercio exterior (desde los años ochenta)

6) Regulaciones a los mercados de capital, impuestos elevados y altos costos de transación que aceleraron la decadencia del sector que la inflación habia impulsionado.

Los siete capítulos del Decreto desregulan sobre

a) Mercados interiores de bienes y servicios

b) Comercio internacional

c) Entes públicos reguladores y la organización estatal.

d) El mercado de capitales.

e) El Sistema de Seguridad Social

f) El régimen laboral

Respecto de los mercados de bienes y servicios, se eliminaron las normas de restricción de oferta, limitaciones al ingreso, restricciones a la información e intervencciones en precios. Se excluyó la regulación de servicios públicos.

Fue modernizada la Ley de Defensa de la Competencia, se suspendió la Ley de Abastecimento (que facultaba al Estado a controlar os precios). Los mercaros abarcados fueron de transporte carretero, concetración de alimentos frescos, 
servicios profesionales, comercialización de fármacos y puertos. En algunos casos, la desregulación requería medidas adicionales desde las provincias.

En materia de comercio internacional, se eliminaron todas las restricciones cuantitativas a la importación, a excepción de cupos para automóviles; también se eliminaron reservas de carga en fletes, fueron simplificados los trámites aduaneros (despacho directo a plaza, registro de operadores, trámites aduaneros) y se procedió al fortalecimiento institucional de la Administración Nacional de Aduana.

En cuanto a entes publicos reguladores, fueron disueltos y sus actividades desreguladas en granos, carnes, explotación florestal, pesca, actividad hípica, yerba mate, azúcar y vitivinicultura.

Se suspendieron los impuestos que solventaban esos entes, la tasa de estadistica a la exportaciones y varios subsidios sectoriales. La estructura de aranceles fue modificada, aunque sofriria retoques posteriores, en dirección a una menor progresividad arancelaria y un menor arancel promedio. El mercado de capitales gozó de disminuciones de impuestos a las transacciones de títulos e valores, equiparación del status de los inversores nacionales y extranjeros, liberación de las comisiones de agentes de bolsa y reformizamiento de la Comisićn. Nacional de Valores en su papel de contralor en el mercado de los valores liwobiliarios.

En el sistema de seguirad social fueron unificados los aportes y disueltas las cajas de asignaciones familiares En materia laboral, por último, se pretendia descentralizar a nivel empresa la negociación salarial.

\subsubsection{Anuncio de medidas de mediano plazo (Teatro Cervantes, oct. 1992)}

En el Teatro Cervantes (Buenos Aires), el Ministro de Economía expuso una serie de metas a mediano plazo (1993-95, es decir lo que restaba, la fecha, del periodo presidencial) en cuanto a politica económica El listado de medidas a implementar se cumplió parcialmente con el anuncio del 01-05-93 del Presidente a la Asemblea Legislativa A la fecha, del listado de medidas hay algunas ya decretadas, algunas próximas a serlo, otras rue dependen de una ley del Congreso y algunas que corresponden a las provincia (Ambito Financiero, 27-04-93 y números posteriores al 01-05-93).

1) Medidas ya decretadas

- Derogación del impuesto a los sellos (jurisdicción federal).

- Rebaja impuesto a los combustibles

- Eliminación de retenciones vigentes a las exportaciones agropecuarias

- Entrega de bonos impositivos por promoción industrial.

- Cambio de regímenes impositivos por promoción industrial.

- Cambic de regímenes promocionales a la Patagonia.

- Aumento de reembolsos (devolución de impuestos indirectos) a las exportaciones.

- Subsidio de tasa de interés en créditos a Pymes.

- Fondo de Garantía suplementaria de crédito para Pymes.

- Apoyo a consorcios de Pymes 
- Reducción de tasas de interés activas en pesos en bancos oficiales a un tope del $2 \%$ mensual.

- Posibilidad de utilizar títulos de deuda pública como garantia de préstamos para adquisición de bienes de capital.

- Régimen de especialización industrial

- Regionalización del INTI.

2) Próximas a ser decretados

- Disminuición de impuestos internos al consumo (relojes, joyas, bebidas alcohólicas, artículos de tocador)

- Financiación del IVA sobre bienes de capital.

- Fondo de bonificación de tasas de exportación para bienes de capital

- Prácticas laborales para recién egresados.

3) Dependen de Ley del Congreso.

- Eliminación del Impuesto a los Activos.

- Disminuición de Impuestos de la nómina salarial

4) Dependen de las Provincias:

- Modificación de los sistemas impositivos provinciales para evitar tributos que penalicen la ncoducción (sellos, ingresos brutos).

\subsubsection{Medidas de cierre de la economía (28-10-92).}

El 28 de octubre de 1992 el Ministerio de Economia anunció la implementación de un paquete de medidas económicas La preocupación de los hombres de la economia era cambiar la rentabilidad relativa de los distintos sectores de la economia sin devaluar el peso. El gobierno apuntó a recomponer las rentabilidades relativas entre sectores, mejorándolas para los bienes exportables y sustitutos de importaciones y encareciendo las importaciones.

En detalle:

1) Se eliminaron los impuestos al gas oil, fuel oil y kerosén (cercanos al $20 \%$ ).

2) Se eliminó la retención (impuestos a la exportación) del 1,5\% que pesaba sobre los productos agropeciarios para financiar al INTA (Instituto Nacionial de Teconlogia Agrpecuária). Se disminuyeron las retenciones la a soja y girasol, que del $6 \%$ pasaron al $3,5 \%$. También las retenciones a los cueros crudos, del $1,5 \%$ pasan al $5 \%$.

3) Se produjo un rescomodamiento de los aranceles, antes en cinco niveles, desde 0 al 35\%, después en ocho, desde 0 al 20\% (Ver Cuadro 31-Anexo Estadistico).

Se elevo la Tasa de Estadistica del 3\% sobre todas las importaciones, al $10 \%$ La Tasa de Estadística no se negocia en las reducciones de aranceles en el Mercosur.

4) Se elevaron los reintegros (devolución de impuesto) a la producción exportable. Serán exactamente iguales a los aranceles de importación que pague el producto respectivo (Ver Cuadro 32 - Anexo Estadistico). 
5) Se introdujercn recortes a la promoción industrial, reembolsos especiales por puertos patagónicos, y privilegios a la producción el Tierra del Fuego. Luego estas medidas se revirtieron parcialmente.

\subsubsection{Anuncios de bimonoetización tras corrida cambiaria (11-92).}

La Autoridad evitó una dolarización traumática de la economia y la insolvencia del sistema financiero, se salvó al sector productivo de tener igual suerte, y se logró separar el problema real del atraso cambiario (que aún susiste), de la viabilidad de la parida nominal establecida por la convertibilidad La conducción económica abortó la corrida que se manifestó en compras de dólares por parte de bancos privados al BCRA, con anuncios acertados, comprometiéndiose a establecer una fluida comunicación entre el segmento del dólar y el de los pesos en el mercado financiero. Con esto buscaba una homogeneidad (sustitutibilidad) mayor entre ambas monedas.

EI BCRA tiene como pasivo contra los tenedores de pesos, la base monetaria, circulante más depósitos a la vista La banca comercial, por su parte tiene como pasivos el M2 (circulante + depósitos a la vista + depósitos en caja de ahorro + depósitos a plazo fijo) menos la base monetária. La diferencia entre M2 y lá base monetaria se lo debe la banca a los particulares. De la deuda del sistema bancario, una proporción muy importante es altamente liquida, rápidamente realizable cuentas corrientes, cajas de ahorro y plazos fijos colocados a períodos breves (un tercio del total de estos). Por su parte los depósitos a la vista y en caja de ahorro en moneda extranjera, rápidamente convertibles, menos sus encajes (bajos) son tambiém pasivo bancario con la comunidad Como los bancos pueden recuperar rápidamente su cartera activa, el bache financiero del conjunto de deberia ser cubierto con emisión monetaria, ya que es impensable que el Banco Central asista impávido a una hecatombe financiera que traería igual secuela sobre las actividades productivas. Esta endogenización de la base monetaria, generaria el incumplimiento de la Ley de Convertibilidad, y la pérdida de la estabilidad con ella lograda

De alli que la potencial insolvencia del sistema financiern, en este escenario de desconfianza generalizada de ios agentes econímicos, es prcisablemente lo que las Autoridades hayan tenido en cuenta cuando decidieron lanzar los anuncios de bimonetización. La salida de la mini-corrida de noviembre fue exitosa.

Se anuncio la autorización a los bancos a operar con cuentas corrientes en dólar y a efectuar la cobertura de los encajes por los depósitos en pesos con la moneda americana.

Estas anticipaciones fueron suficientes pra convencer que no habria devaluación, ante los malos resultados de la cuenta corriente que iban siendo conocidos, y que si los agentes lo demandan se les entregarían las divisas que respaldan la base monetaria. Esta mayor confianza en la permanencia de la paridad nominal se transladó automáticamente al mercado del call en forma de una menor tasa de intéres.

De no haberse anunciado la profundización de la biomonetización, la tasa de intéres hubiera continuado en forma ascendente, siguiendo la tendencia que adquirió dırante la corrida, y fenandose hipotéticamente cuando hubiera crecido a 
niveles siderales. Una intensa recesión hubiera sobrevenido entonces, y quizás hasta una deflación que pusiera en línea los precios relativos domésticos con los del ordern internacional.

Sin embargo la solución "natural" recessiva, que provee la convertibilidad cuando cae la demanda de dinero doméstico, en inviable. En efecto, el costo de empleo y producción perdida no era digerible para el equipo económico por razones técnicas y políticas, las primeras, por el carácter profundamente procíclico de la recaudación impositiva, que hubiera caído en picada junto con la actividad; las segunda por la elecciones parlamentarias de 1993

El reciente retoque efectuado en la política comercial externa fue el disparador de las acciones de mini-corrida en el mercado cambiario

\subsubsection{Profundización de la bimonetización (31-03-93)}

El equipo económico efectuó una serie de anuncios sobre el final de enero de 1993, que consolidarcn la marcha del programa econónico.

1) Se eliminó la possibilidad de constituir depósitos a plazo fijo por periodos menores de 30 dias. Se trataba al momento de $56 \%$ aproximado del total de plazos fijos, que tenian obligaciones de encajes por un $26 \%$ del total ( $7-14$ dias), y del $20 \%$ respectivamente (15-29 días).

2) Los depósitos a más de 30 dias, con encajes muy pequeños antes de la reforma ( $3 \%$ plazos más breves y $2 \%$ plazos más prolongados), fueron de la posibilidad de constituir encajes legales.

3) Por su parte, las imposiciones en cuenta corriente, cuyos encajes eran del $71 \%$ y las cajas de ahorro, $20 \%$ antes de la reforma, vieron reducidas la reservas requeridas a un $40 \%$.

Las nuevas disposiciones habilitaron a las entidades a abrir cuentas de ahorro a empresas, antes operatoria solamente dirigidas a personas fisicas. Por el lado de los depósitos en dólares, se eliminaron las imposiciones "a la vista", para obligar el translado de ese segmento a depósitos en cuenta corriente y se fijaron encajes para estcs y para las cajas de ahorro en dólares, iguales a los del segmento de pesos.

\subsubsection{Medidas anunciadã ante la Asamblea Legislativa (01-05-93)}

Algumas ya anuncidas en el Teatro Cervantes. El objetivo central de aquellas fue la elevación de la tasa de crecimiento de la productividad, al subsidiar la acumulación de capital con la eliminación de tributos aduaneios a los bienes de capital importados y la aplicación de reintegros a los producidos localmente, como medida más destacada.

También apunta a mejorar las condiciones de sectores productivos en dificultades:

- Actividad Agropecuaria

- Pequenas y medianas empresas

- Algunas producciones muy afectadas por la apertura de la economia (siderurgia, papel, etc.). 
El detalle de las medidas, extractadas de Ambito Fianciero (03-05-93) es el siguiente:

- Arancel cero y Tasa de Estadistica cero para la importación de bienes de capital (ver Cuadro 31-Anexo Estadístico).

- Reintegro estatal del $15 \%$ del valor a la producción de bienes de capital nacionales.

- Suspensión de los antecipos del Impuesto a los Activos (el Congreso debe decidir su eliminación por Ley).

- Simplificación del pago de impuestos del Sector Agropecuario.

- Baja de los antecipos a cuenta del IVA ganadero.

- Créditos de reconversión a Pymes.

- Anuncio de nueva legislación laboral flexible.

- Anuncios de elevación de los gastos estatales en investigación y desarollo, apoyo a reetranamiento de trabajadores y pasantias para recién egresados.

- Inversiones estatales en transporte vial y subsidios del mismo origen al transporte ferroviario de carga.

\section{ANEXO ESTADISTICO}

Cuadro 1 - Tasas de crecimiento del

PBI e inflación (IPC) - Promedios anuales (\%)

\begin{tabular}{r|r|r|r|r|r}
\hline Periodo & \multicolumn{1}{|c|}{ PBI } & \multicolumn{1}{|c|}{ IPC } & Periodo & \multicolumn{1}{|c|}{ PBI } & \multicolumn{1}{|c|}{ IPC } \\
\hline $1914-19$ & 0,26 & 9 & $1980-84$ & $-1,08$ & 274,00 \\
$1920-24$ & 7,33 & -3 & 1984 & 1,80 & 688,00 \\
$1925-29$ & 4,46 & -1 & 1985 & $-6,60$ & 385,40 \\
$1929-34$ & $-0,36$ & -4 & 1986 & 7,30 & 81,90 \\
$1935-39$ & 3,32 & 3 & 1987 & 2,60 & 174,80 \\
$1940-44$ & 3,70 & 6 & 1988 & $-1,90$ & 387,70 \\
$1945-49$ & 4,20 & 18 & 1989 & $-6,20$ & $4.923,30$ \\
$1950-54$ & 1,90 & 22 & 1990 & 0,10 & $1.343,90$ \\
$1955-59$ & 2,94 & 41 & 1991 & 8,90 & 84,00 \\
$1960-64$ & 4,26 & 23 & 1992 & 8,70 & 17,50 \\
$1965-69$ & 5,05 & 20 & $1985-89$ & $-0,96$ & $1.190,62$ \\
$1970-74$ & 5,18 & 40 & $1990-92$ & 5,90 & 481,80 \\
$1975-79$ & 1,53 & 223 & & & \\
\hline
\end{tabular}

Fuente: PBI: Conesa, 1992 (hasta 1984) y BCRA (ultimas estimaciones PBI 1984/92). Precios: INDEC

Cuadro 2 - Renta por habitante en 1929 (U\$S)

\begin{tabular}{l|r|r|r}
\hline Paises & Renta por habitante & Países & Renta por habitante \\
\hline 1) Estados Unidos & 590 & Francia & 310 \\
2) Canadá & 550 & Alemania & 292 \\
3) Gran Bretaña & 502 & Italia & 152 \\
4) Australia & 476 & España & 127 \\
5) Suiza & 463 & Japón & 102 \\
6) Argentina & 446 & & \\
\hline
\end{tabular}

Fuente: 50 .000 días de Bolsa de Com., Bolsa de Comercio de Buenos Aires. Citado por Casas (1991) 
Cuadro 3 - Participación argentina en las exportaciones mundiales (\%)

\begin{tabular}{c|c|c|c}
\hline Periodo & Porcentaje & Periodo & Participación \\
\hline $1928 / 30$ & 2,70 & 1970 & 0,63 \\
$1947 / 50$ & 2,20 & 1980 & 0,43 \\
1960 & 0,96 & 1988 & 0,45 \\
\hline
\end{tabular}

Cuadro 4 - Déficit fiscal y cuasifiscal como porcentaje del PBI,1960-85

\begin{tabular}{c|r|r|r|r|r}
\hline Año & Déficit fiscal & Déficit cuasifiscal & Año & Déficit fiscal & Déficit cuasifiscal \\
\hline 1960 & 3,45 & 1,77 & 1973 & 7,64 & $-1,06$ \\
1961 & 3,44 & $-0,44$ & 1974 & 7,13 & $-3,93$ \\
1962 & 6,37 & $-2,74$ & 1975 & 14,49 & $-3,41$ \\
1963 & 6,34 & 0,07 & 1976 & 8,58 & 2,25 \\
1964 & 5,25 & $-1,33$ & 1977 & 3,26 & $-0,42$ \\
1965 & 2,55 & 0,39 & 1978 & 4,00 & 2,34 \\
1966 & 3,31 & $-0,55$ & 1979 & 3,88 & 2,83 \\
1967 & 1,06 & 1,42 & 1980 & 4,66 & $-0,87$ \\
1968 & 1,66 & $-0,17$ & 1981 & 6,36 & 0,22 \\
1969 & 1,06 & $-0,39$ & 1982 & 5,59 & 25,45 \\
1970 & 1,15 & $-0,06$ & 1983 & 10,69 & 4,87 \\
1971 & 3,72 & $-1,09$ & 1984 & 7,65 & 17,46 \\
1972 & 5,05 & 0,18 & 1985 & 2,18 & 7,40 \\
\hline
\end{tabular}

Cuadro 5 - Dólar: cierre al fin de cada mes, libre tipo vendedor. En australes (desde enero de 1992, A $10.000=\$ 1$ )

\begin{tabular}{l|r|r|r}
\hline \multicolumn{1}{c|}{ Mes } & 1988 & \multicolumn{1}{|c}{1989} & 1990 \\
\hline Enero & 5,50 & 17,70 & 1.870 \\
Febrero & 6,18 & 28,20 & 5.850 \\
Marzo & 6,40 & 48,50 & 4.650 \\
Abril & 7,34 & 80,50 & 4.930 \\
Mayo & 9,22 & 240,00 & 5.000 \\
Junio & 11,36 & 520,00 & 5.315 \\
Julio & 12,62 & 660,00 & 5470 \\
Agosto & 14,40 & 66200 & 6.270 \\
Septiembre & 14,88 & 648,00 & 5.730 \\
Octubre & 15,11 & 723,00 & 5.570 \\
Noviembre & 15,61 & $1.010,00$ & 5.200 \\
Diciembre & 16,41 & $1.950,00$ & 5.820 \\
\hline Fuente: Ambito Financiero
\end{tabular}

Cuadro 6 - Hiperinflación de 1989

\begin{tabular}{c|r|r|r|r}
\hline Periodo & $\begin{array}{c}\text { IPC - aumento } \\
\text { mensual (\%) }\end{array}$ & $\begin{array}{c}\text { Base monetaria } \\
\text { aumento (\%) }\end{array}$ & $\begin{array}{c}\text { Salario real de la } \\
\text { administración }\end{array}$ & $\begin{array}{c}\text { Déficit } \\
\text { operativo \% / } \\
\text { ingresos }\end{array}$ \\
\hline Abr 1989 & 33,4 & 27,2 & 91,0 & 146,8 \\
May 1989 & 78,5 & 108,4 & 98,6 & 114,7 \\
Jun 1989 & 114,5 & 84,2 & 78,2 & 23,8 \\
Jul 1989 & 196,6 & 144,6 & 101,2 & 34,3 \\
Ago 1989 & 37,9 & 29,8 & 54,3 & 5,4 \\
\hline
\end{tabular}


Cuadro 7 - Hiperinflación de 1990

\begin{tabular}{c|r|r|r|r}
\hline Periodo & $\begin{array}{c}\text { IPC - aumento } \\
\text { mensual (\%) }\end{array}$ & $\begin{array}{c}\text { Base monetaria } \\
\text { aumento (\%) }\end{array}$ & $\begin{array}{c}\text { Salario real de la } \\
\text { administración }\end{array}$ & $\begin{array}{c}\text { Déficit } \\
\text { operativo \% / } \\
\text { ingresos }\end{array}$ \\
\hline Dic 1989 & 40,1 & 36,2 & 78,8 & $-2,3$ \\
Ene 1990 & 79,2 & 35,5 & 69,1 & $-25,3$ \\
Feb 1990 & 61,6 & 18,8 & 66,0 & $-22,3$ \\
Mar 1990 & 95,5 & 56,6 & 43,3 & $-18,3$ \\
\cline { 2 - 3 } & 693,2 & & \\
\hline
\end{tabular}

Fuente. FIEL, citado por Casas (1991).

Cuadro 8 - Dólar. cierre al fin de cada mes, libre tipo vendedor. 1991 en australes, 1992 en pesos (A 10:000 =\$1)

\begin{tabular}{l|r|r|r}
\hline \multicolumn{1}{c|}{ Mes } & 1991 & \multicolumn{1}{|c|}{1992} & \multicolumn{1}{c|}{1993} \\
\hline Enero & 9.300 & 0,9901 & 0,9992 \\
Febrero & 10.300 & 0,9900 & 0,9992 \\
Marzo & 9.640 & 0,9935 & 0,9998 \\
Abril & 9.835 & 0,9896 & \\
Mayo & 9.925 & 0,9896 & \\
Junio & 9.995 & 0,9916 & \\
Julio & 9.975 & 0,9920 & \\
Agosto & 9.975 & 0,9911 & \\
Septiembre & 9.905 & 0,9912 & \\
Octubre & 9.915 & 0,9912 & \\
Noviembre & 9.910 & 0,9930 & \\
Diciembre & 10.030 & 0,9975 & \\
\hline
\end{tabular}

Fuente: Ambito Finaciero

Cuadro 9 - Evoluición del PSI en los últimos años. Ultimas estimaciones del BCRA

\begin{tabular}{c|r|r|r|r}
\hline Años & $\begin{array}{c}\text { PBI a precios } \\
\text { constantes de 1986 }\end{array}$ & $\begin{array}{r}\text { Indice táse } \\
1992=100\end{array}$ & $\begin{array}{r}\text { PBI millones de } \\
\text { \$ de 1992 }\end{array}$ & $\begin{array}{c}\text { Tasa \% de } \\
\text { aumento anual }\end{array}$ \\
\hline 1980 & $12.111,77$ & 92,41 & $209.438,02$ & \\
$i 981$ & $11.422,43$ & 87,15 & $197.517,76$ & $-5,7$ \\
1982 & $11.068,49$ & 84,45 & $191.397,48$ & $-3,1$ \\
1983 & $11.478,73$ & 87,58 & $198.491,31$ & 3,7 \\
1984 & $11.685,81$ & 89,16 & $202.072,22$ & 1,8 \\
1985 & $10.915,15$ & 83,28 & $188.745,79$ & $-6,6$ \\
1986 & $11.712,02$ & 89,36 & $202.525,50$ & 7,3 \\
1987 & $12.020,67$ & 91,69 & $207.806,21$ & 2,6 \\
1988 & $11.789,35$ & 89,95 & $203.862,68$ & $-1,9$ \\
1989 & $11.059,32$ & 84,38 & $191.238,83$ & $-6,2$ \\
1990 & $11.071,11$ & 84,74 & $191.442,80$ & 0,1 \\
1991 & $12.056,73$ & 91,99 & $208.486,13$ & 8,9 \\
1992 & $13.106,56$ & 100,00 & $226.640,00$ & 8,7 \\
\hline
\end{tabular}

Fuente: BCRA (citado en Ambito Financiero). Elaboración propia columnas 2 y 3 
Cuadro 10 - Evolución de la Inversión Bruta

Interna (IBI) en los últimos años. Ulitimas estimaciones del BCRA.

\begin{tabular}{c|r|r|r|r}
\hline Años & $\begin{array}{c}\text { IBI a precios } \\
\text { constantes de 1986 }\end{array}$ & $\begin{array}{r}\text { Indice base } \\
1992=100\end{array}$ & $\begin{array}{c}\text { IBI millones de } \$ \\
\text { de 1992 }\end{array}$ & $\begin{array}{c}\text { Tasa \% de } \\
\text { aumento anual }\end{array}$ \\
\hline 1980 & $2.748,80$ & 125,51 & $47.504,12$ & $-16,3$ \\
1981 & $2.299,60$ & 105,06 & $39.764,03$ & $-16,4$ \\
1982 & $1.921,50$ & 87,78 & $33.223,74$ & $-0,7$ \\
1983 & $1.907,10$ & 87,12 & $32.973,94$ & $-3,4$ \\
1984 & $1.841,90$ & 84,15 & $31.849,83$ & $-17,8$ \\
1985 & 1513,40 & 69,14 & $26.168,71$ & 15,2 \\
1986 & $1.743,40$ & 79,65 & $30.146,63$ & 14,8 \\
1987 & $2.002,10$ & 91,46 & $34.616,58$ & $-2,00$ \\
1988 & 1962,20 & 89,64 & $33.927,73$ & $-24,4$ \\
1989 & $1.483,50$ & 67,77 & $25.650,18$ & $-9,9$ \\
1990 & $1.336,10$ & 61,04 & $23.102,95$ & 25,1 \\
1991 & $1.671,90$ & 76,38 & $28.908,97$ & 30,9 \\
1992 & $2.188,80$ & 100,00 & $37.848,88$ & \\
\hline
\end{tabular}

Fuente $B C R A$ (citado en Ambito Financiero). Elaboración propia columnas 2 y 3

Cuadro 11 - |BI como porcentaje del PBI

\begin{tabular}{c|c|c|c}
\hline Años & $\%$ & Anõs & $\%$ \\
\hline 1980 & 25,3 & 1987 & 19,6 \\
1981 & 22,7 & 1988 & 18,6 \\
1982 & 21,8 & 1989 & 15,5 \\
1983 & 20,9 & 1990 & $14,0^{*}$ \\
1984 & 20,0 & 1991 & $14,0^{*}$ \\
1985 & 17,6 & 1992 & $16,7^{\star}$ \\
1986 & 17,5 & & \\
\hline
\end{tabular}

Fuente: BCRA (citado en Ambito Financiero)

Nota* Preliminar

Cuadro 12 - Evolución de la producción industrial

\begin{tabular}{c|c|c}
\hline Años & Var. respecto al año anterior $(\%)$ & Indice 1988=100 \\
\hline 1989 & $-9,8$ & 90,20 \\
1990 & $-0,9$ & 89,38 \\
1991 & 12,7 & 100,73 \\
1992 & 12,0 & 112,81 \\
\hline
\end{tabular}

Fuente: Ministerio de Economia, sobre datos del sector privado, Ambito Financiero, 25-02-93. 
Cuadro 13 - Variación porcentual por trimestre del indice de producción industrial con estacionalidad (IPI - FIEL) respecto trimestre del año anterior

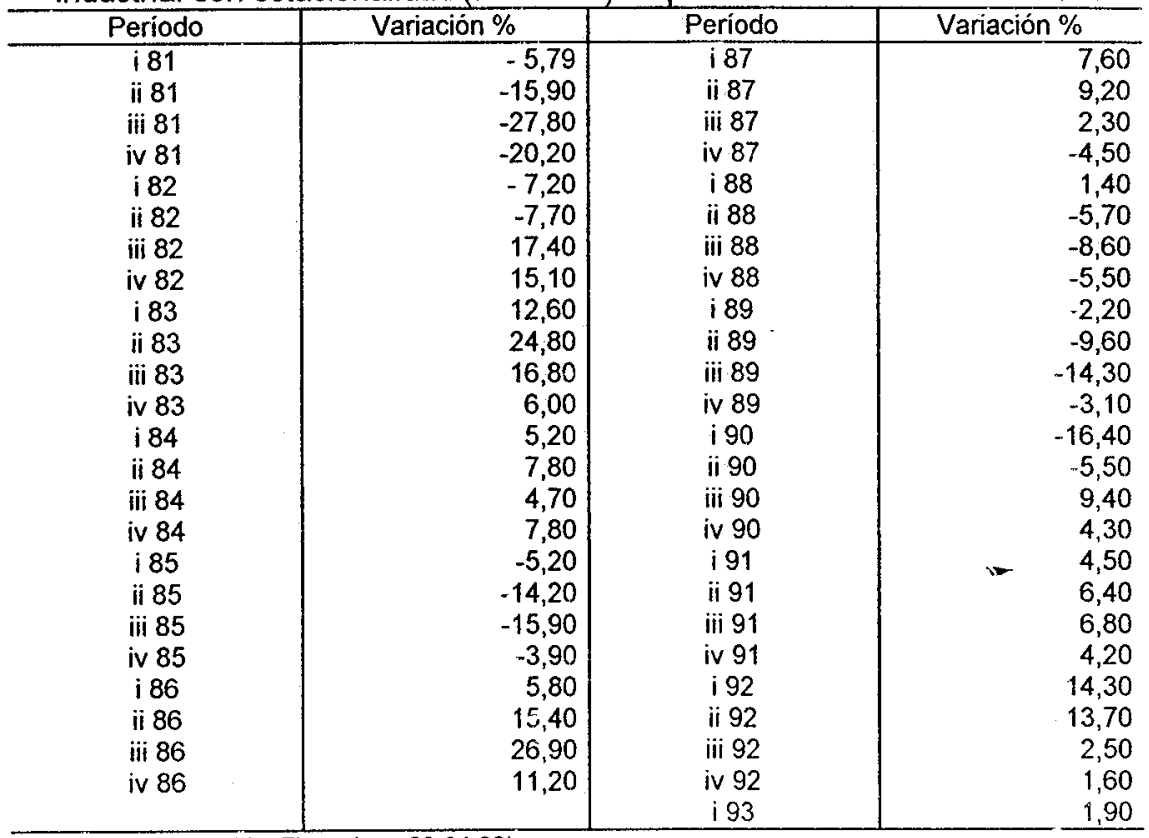

Fuente: FlEL (Ambito Financiero, 23-04-93)

Cuadro 14: Composición sectorial del PBI. Porcentaje sobre total

\begin{tabular}{l|r|r|r}
\hline \multicolumn{1}{c|}{ Sectores } & 1990 & 1991 & \multicolumn{1}{|c|}{1992} \\
\hline Agricultura, caza, silv. y pesca & 8,1 & 6,7 & 6,0 \\
Minas y canteras & 2,9 & 2,1 & 1,8 \\
Industria manufacturera & 26,8 & 24,4 & 21,9 \\
Electricidad, gas y agua & 1,9 & 1,6 & 1,7 \\
Construcción & 4,7 & 4,7 & 5,3 \\
Comercio, rest. y hoteles & 14,5 & 15,2 & 15,3 \\
Transporte, almacen. y comunic & 5,2 & 5,2 & 5,2 \\
Est. financ, seguros y bienes inmuebles & 14,9 & 15,3 & 16,8 \\
Servicios com., soc. y personales & 21,3 & 24,8 & 26,0 \\
\hline
\end{tabular}

Fuente: BCRA (citado en El economista, mayo 1993) 
Cuadro 15 - Tasas de desocupación y subocupación

\begin{tabular}{c|c|c|c}
\hline Periodo & $\begin{array}{c}\text { 1) Desocupación } \% \\
\text { sobre la PEA }\end{array}$ & $\begin{array}{c}\text { 2) Subocupación } \% \\
\text { sobre la PEA }\end{array}$ & $\begin{array}{c}\text { 3) Total 1+2 \% } \\
\text { sobre la PEA }\end{array}$ \\
\hline oct 86 & 5,2 & 7,4 & 12,6 \\
abr 88 & 6,5 & 8,9 & 15,4 \\
abr 89 & 8,1 & 8,6 & 16,7 \\
oct 89 & 7,1 & 8,6 & 15,7 \\
abr 90 & 8,6 & 9,3 & 17,9 \\
oct 90 & 6,2 & 8,7 & 14,9 \\
abr 91 & 6,9 & 8,6 & 15,5 \\
oct 91 & 6,0 & 7,9 & 13,9 \\
may 92 & 6,9 & 8,3 & 15,2 \\
oct 92 & 7,0 & 8,1 & 15,1 \\
\hline
\end{tabular}

Fuente: INDEC (EI Economista, Un año en la Argentina y el Mundo, edición 1993)

Cuadro 16: La Población Económicamente Activa en octubre 1992.

\begin{tabular}{l|r}
\hline \multicolumn{1}{c|}{ Clasificación } & \multicolumn{1}{c}{ Numero de personas } \\
\hline 1) Desocupados & 793.000 \\
2) Subocupados & 917.000 \\
3) Problemas de empleo $(1+2)$ & 1.710 .000 \\
4) Ocupados plenos & 9618.000 \\
5) PEA (3+4) & 11.328 .000 \\
\hline
\end{tabular}

Fuente INDEC (citado por Ambito Financiero)

Cuadro 17 - Sector público no financiero.

El resultado de 1992 y las metas a cumplir. (U\$S 1.000.000)

\begin{tabular}{l|r|r|r}
\hline & 1992 (real) & 1993 (proy) & \multicolumn{1}{|c}{$\begin{array}{c}1994 \\
\text { (proy) }\end{array}$} \\
\hline I Superávit fiscal primario & 4.916 & 4.752 & 4.669 \\
Sin privatizaciones & 3.125 & 4.902 & 4.169 \\
Privatizaciones & 1.781 & 350 & 1.000 \\
Quebrantos impuestos a las ganancias & 0 & $(500)$ & $(500)$ \\
\hline II Intereses deudas (netos) & 3615 & 2.839 & 3.064 \\
Externos SPNF & 2.984 & 2.667 & 3.047 \\
Externos BCRA & 684 & 259 & 359 \\
Internos & 340 & 333 & 219 \\
Cobrados BCRA & $(395)$ & $(420)$ & $(561)$ \\
\hline III Superávit después de intereses & 1.301 & 1.913 & 1.605 \\
\hline IV Amortización Deuda & 0 & 3.565 & \\
Externa & 0 & 152 & 0 \\
Interna & 2.649 & 3.446 & 2.516 \\
\hline VFinanciamento & 1.180 & 228 & 122 \\
Intereses refinanciados & 1.469 & 3.218 & 2.394 \\
Desembolsos & $(1.117)$ & $(271)$ & $(127)$ \\
\hline VIIV+V & $(416)$ & 1.642 & 1.478 \\
\hline VIIIII VI & & & \\
\hline
\end{tabular}

Fuente: M\&S Consultores Ambito Financiero, 15-03-93 
Cuadro 18: Evolución del gasto sector público consolidado.

\begin{tabular}{c|r|r|r}
\hline Periodo & $\begin{array}{r}\text { Millones de dólares } \\
\text { de 1992 }\end{array}$ & Período & $\begin{array}{c}\text { Millones de dólares } \\
\text { de 1992 }\end{array}$ \\
\hline Prom-1961-72 & 44.599 & 1983 & 42.522 \\
1973 & 49.051 & 1984 & 45.397 \\
1974 & 62.804 & 1985 & 37.585 \\
1975 & 57.250 & 1986 & 42.708 \\
1976 & 53.250 & 1987 & 42.796 \\
1977 & 41.407 & 1988 & 43.084 \\
1978 & 57.442 & 1989 & 30.286 \\
1979 & 73.666 & 1990 & 41.011 \\
1980 & 102.965 & 1991 & 54.154 \\
1981 & 93.163 & 1992 & 55.907 \\
1982 & 45.004 & $1993^{*}$ & 60.703 \\
\hline
\end{tabular}

Fuente: Ambito Financiero, 21-04-93

Nota: * Proyectado

Cuadro 19: Ingresos, egresos y déficit del sector público nacional. Miles de millones de dólares de 1992

\begin{tabular}{l|r|r|r|r|r}
\hline \multicolumn{1}{r|}{ Item } & \multicolumn{1}{|c|}{1988} & \multicolumn{1}{c}{1991} & \multicolumn{1}{c|}{1992} & 1993 & 1994 \\
\hline Ingresos totales & 25,5 & 29,1 & 37,7 & 41,4 & 44,7 \\
\hline Gastos totales & 31,8 & 30,8 & 37,7 & 41,4 & 44,7 \\
\cline { 2 - 6 } Nación & 16,8 & 12,4 & 13,7 & 15,3 & 16,9 \\
Salarios & 4,0 & 4,0 & 4,3 & 4,8 & 5,3 \\
Bienes y servicios & 1,7 & 1,5 & 1,6 & 1,7 & 1,8 \\
Inversiones & 4,5 & 1,9 & 2,5 & 3,2 & 4,2 \\
Intereses & 4,8 & 3,0 & 3,0 & 3,3 & 3,3 \\
Otros & 1,8 & 2,0 & 2,3 & 2,3 & 2,3 \\
Provincias & 7,9 & 9,3 & 12,1 & 13,0 & 13,6 \\
Jubilados y pens. & 7,1 & 9,1 & 11,9 & 13,1 & 14,2 \\
\hline Déficit & 6,3 & 1,7 & 0 & 0 & 0 \\
\hline
\end{tabular}

Fuente: Presentación de Cavallo ante el Congresso 12-02-92 Citado por Conesa, 1992

Cuadro 20 - Situación del sector público no financiero (SPNF). (U\$S 1.000.000)

\begin{tabular}{l|r|r|r|r}
\hline \multicolumn{1}{c|}{ Periodo } & $\begin{array}{c}\text { Superavit } \\
\text { operativo }\end{array}$ & $\begin{array}{c}\text { Recursos de } \\
\text { capital }\end{array}$ & $\begin{array}{c}\text { Superavit } \\
\text { primario }\end{array}$ & \multicolumn{1}{c}{$\begin{array}{c}\text { Servicio } \\
\text { deuda }\end{array}$} \\
\hline 1991 & -369 & 305 & -64 & 1.376 \\
Ene/Feb* & 219 & 342 & 561 & 277 \\
Mar/May & 354 & 635 & 989 & 739 \\
Jun/Ago & 1.093 & 641 & 1.734 & 482 \\
Sep/Nov & & & & \\
1992 & 825 & 1.007 & 1.832 & 1.460 \\
Ene/Feb* & 664 & 221 & 885 & 1.012 \\
Mar/May & 743 & 164 & 907 & 831 \\
Jun/Ago & 517 & 216 & 833 & 743 \\
Sep/Nov & & & \\
\hline
\end{tabular}

Fuente: El Economista. Un año en la Argentina y el Mundo, edición 1993.

Nota: * incluye diciembre del año anterior. 
Cuadro 21 - Inversión en bienes y servicios públicos. Millones de $\$$

\begin{tabular}{l|r|r}
\hline & 1992 & \multicolumn{1}{|c|}{1993} \\
\hline Sector público nacional & $2.063,7$ & $2.641,1$ \\
Provincias y municipios (transf. nación) & $1.276,0$ & $1.298,5$ \\
Provincias y municipios (fondos propios) & $2.022,5$ & $2.742,0$ \\
Empresas privatizadas y concesionadas & $1.558,0$ & $2.712,0$ \\
\hline Total & $6.920,2$ & $9.393,7$ \\
\hline
\end{tabular}

Fuente Ministerio de Economia (Citado en El Cronista, 19-05-93)

Cuadro 22 a: Recaudación tributaria en 1992. Millones de $\$$

\begin{tabular}{l|r}
\hline 01) DGI (2+3+5+7) & 23.670 \\
02) Coparticipados bruto & 17.786 \\
Coparticipados neto (a) & 16.683 \\
Ganancias (coparticipado) & 1.848 \\
Ganancias (total) & 2.537 \\
Activos (1\%) (tcaps) & 376 \\
IVA (neto) 89\% & 11.637 \\
IVA (total bruto) & 13.348 \\
Reembolsos & -274 \\
IVA (neto) 100\% & 13.075 \\
Internos & 2.154 \\
Débitos bancarios & 659 \\
Otros + presentación espontánea & 1.112 \\
03) Combustibles & 2.474 \\
04) No coparticipados (5+6) & 2.399 \\
05) Sellos & 411 \\
06) Aduana & 1.988 \\
Derechos de importación & 1.421 \\
Derechos de exportación & 56 \\
Tasa de estadistica & 512 \\
07) Asignación especifica & 4.103 \\
08) DGl + Aduana (1+6) & 25.658 \\
09) Sistemas de seguridad social & 10.305 \\
Aportes y contribuciones & 8.575 \\
PAMl y ANSSAL & 1.730 \\
10) Ré caudación total (8+9) & 35.963 \\
DESTiNO & \\
Tesouro Nacional (b) & 10.854 \\
Cuentas Especiales (c) & 2.987 \\
Provincias (d) & 10.890 \\
Sistema de Seguridad Social (e) & 10.307 \\
15\% de coparticipados para SSS & 927 \\
\hline
\end{tabular}

Fuemie: Secretaria de ingresos públicos (El Economista, Un año en la argentina y el Mundo, ed 1993).

Notas: (a) Neto de $15 \%$ para Seguridad Social y suma fija para un fondo de provincias, desde 09192 (b) $42,34 \%$ de los impuestos coparticipados, el total de los no coparticipados menos $10 \%$ de la Tasa de Estadistica, $38 \%$ de Combustibles, 33\% de Divisas (incluido en Otros), 35\% de Activos Educación, Aporte de Empresas Públicas y Ahorro Obligatorio. (c) $42 \%$ de Combustibles para FONAVI, ANSSAL y PAMI, 100\% de los ingresos de Tercero Usos - SSS - y otros. Modificaciones de julio de 1922: $42 \%$ de Combustibles va al Tesoro, $17 \%$ a Provincias y el $41 \%$ a Cuentas Especiales. IVA SSS: $90 \%$ al SSS y $10 \%$ a Provincias (d) $57,66 \%$ de Compaticipados, Fondo de Desequilibrios Provinciales, $65 \%$ de Activos (Asignación Especifica), $67 \%$ del Impuesto a las Divisas, $13 \%$ de Combustibles, $100 \%$ de Ganacias para Provincias, $5 \%$ del IVA para Seguridad Social, $10 \%$ de Bienes Personales y a partir de septiembre 40,3 millones de Fondo para Provincias, e) Incluye los Aportes y Contribuiciones, $90 \%$ IVA SSS, $90 \%$ de Bienes Personales, $100 \%$ de Ganancias para SSS 
Cuadro 23: Evolución de la alícuota del IVA: 1989-1993

\begin{tabular}{l|c}
\multicolumn{1}{c|}{ Periodos } & Alíquota (\%) \\
\hline enero 1989 - marzo 1990 & 15,0 \\
marzo 1990 - diciembre 1990 & $13,0^{*}$ \\
diciembre 1990 - abril 1991 & 15,6 \\
abril 1991 - abril 1992 & 16,0 \\
abril 1992 - ... & 18,0 \\
\hline
\end{tabular}

Fuente: Ambito Financiero, 05-02-93 Nota: * generalización.

Cuadro 24: Privatizaciones en 1991 y 1992. (U\$S 1.000:000)

\begin{tabular}{|c|c|c|}
\hline Item & Efectivo & Deuda \\
\hline 1991 & \multicolumn{2}{|c|}{ Concesión } \\
\hline Estaciones de radio & 3,7 & $12^{\star}$ \\
\hline Venta Hotal Llao Llao & 999 & \\
\hline Areas petroleras & \multicolumn{2}{|c|}{ Concesión } \\
\hline FFCC Rosario-Bahia Blanca $(5.278 \mathrm{~km})$ & 830 & \\
\hline TANDANOR, talleres navales & 59,8 & \\
\hline 1992 & & \\
\hline Areas petroleras & 531,9 & \\
\hline YPF SA, refinaria Campo Durán & 64,1 & \\
\hline ENTEL, acciones TELECOM & 1.226,9 & \\
\hline Petroquímica Rio Tercero & 7.3 & \\
\hline FFCC Mitre $(5.021 \mathrm{~km})$ & \multicolumn{2}{|c|}{ Concesiön } \\
\hline SEGBA Usina Central Puerto & 92,2 & \\
\hline Altos Hornos Zapla & 3,3 & $29,7^{\star}$ \\
\hline SEGBA, Usina Central Costanera & 90,1 & \\
\hline Mercado de Hacienda de Liniers & \multicolumn{2}{|c|}{ Concevión } \\
\hline SEGBA, distribuidora EDENOR & 30 & 397,9 \\
\hline SEGBA, distribuidora EDESUR & 30 & 481 \\
\hline Elevador puerto de Quequén & $2,9+$ Canon & \\
\hline Elevador puerto Buenos Aires & $1,1+$ Canon & \\
\hline AyE, Central Alto Valle & 22,1 & \\
\hline FFCC, ramal Detta-Borges & \multicolumn{2}{|c|}{ Concesión } \\
\hline AyE, Central General Güemes & 10 & 76,2 \\
\hline Elevador puerto de Diamante & 2 & \\
\hline FFCC Roca $(4620 \mathrm{~km})$ & \multicolumn{2}{|c|}{ Concesión } \\
\hline Hipódromo Argentino & \multicolumn{2}{|l|}{$61,5+$ Canon } \\
\hline SEGBA, central Dock Sur & 25 & \\
\hline SEGBA, Central Pedro de Mendoza & 8,5 & \\
\hline SOMISA & 140 & $12,4 *$ \\
\hline FFCC Urquiza $(3.200 \mathrm{~km})$ & \multicolumn{2}{|c|}{ Concesión } \\
\hline SEGBA, distribuidora EDELAP & 5 & 134 \\
\hline GAS Transportadora del Sur & 100 & 256,1 \\
\hline GAS Transportadora del Norte & 28 & 182,2 \\
\hline GAS Distribuidora Pampeana & 18 & 217,4 \\
\hline GAS Distribuidora del Litoral & 14 & 89,6 \\
\hline GAS Distribuidora del Centro & 18 & 120 \\
\hline GAS Distribuidora Cuyana & 26 & 96 \\
\hline GAS Distribuidora Sur & 14 & 134 \\
\hline GAS Distribuidora Noroeste & 10 & 62 \\
\hline GAS Distribuidora Metropolitana & 44 & 256 \\
\hline GAS Distribuidora Buenos Aires N & 28 & 127,5 \\
\hline OSN & & \\
\hline AyE, Central Sorrento & 5 & 3,8 \\
\hline Inmuebles hasta $04-05-93$ & $149,7(\mathrm{Amb}$ & \\
\hline
\end{tabular}

Fuente: Subsecretaria de Privatizaciones (El Economista, Un año en la Argentina y el Mundo, edición 1993)

Nota. Títulos valor nominal, en los casos siguientes, equivalente en efectivo 


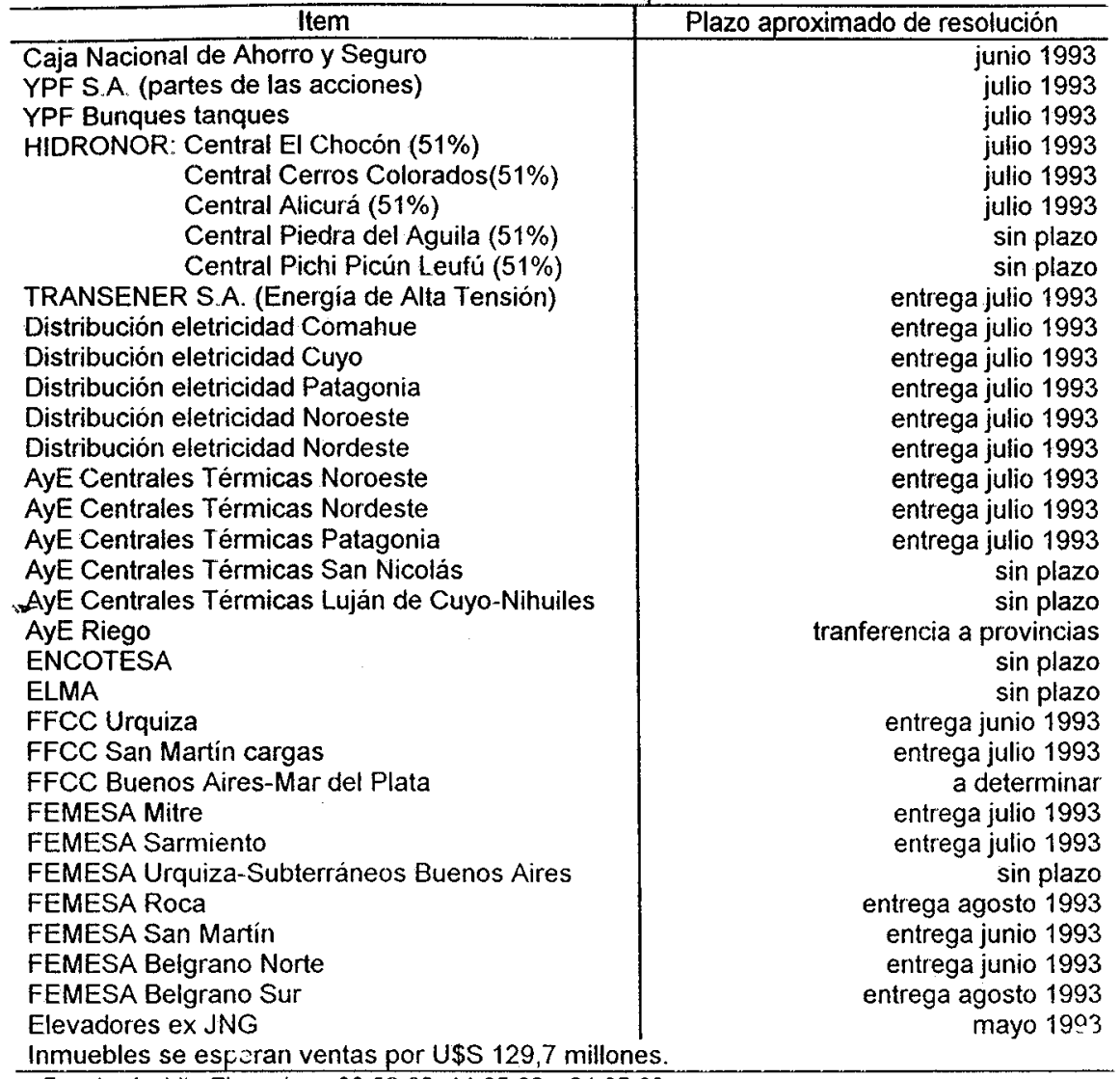

Fuente: Ambito Financiero, 09-02-93, 14-05-93 y 24-05-93

Cuadro 26: Evolución de la deuda pública argentina (U\$S 1.000.000)

\begin{tabular}{c|r|r|r}
\hline Año & Deuda Interna & Deuda Externa & Total \\
\hline 1988 & 29.175 & 51.460 & 80.635 \\
1989 & 25.975 & 53.405 & 79.380 \\
1990 & 24.650 & 53.625 & 78.275 \\
1991 & 20.985 & 53.720 & 74.705 \\
1992 & 20.070 & 51.905 & 71.975 \\
$1993^{*}$ & 17.420 & 47.880 & 65.300 \\
\hline
\end{tabular}

Fuente: Macroeconómica. Ambito Financiero, 19-03-93

Nota: * estimada 
Cuadro 27: EI Plan Brady Argentino. (U\$S 1.000.000)

\begin{tabular}{|c|c|c|c|}
\hline Bonos & Monto & Amortización & Cupón anual \\
\hline Descuento (Discount) & 4.500 & 30 años, al vencimiento & $\begin{array}{l}\text { LIBOR + 13/16\% } \\
\text { semestralmente }\end{array}$ \\
\hline $\begin{array}{l}\text { Par } \\
\text { (Par Bonds) }\end{array}$ & 15000 & 30 años, al vencimiento & $\begin{array}{l}\text { Año 1: } 4 \% \\
\text { Año 2. } 4,25 \% \\
\text { Año 3: } 5 \% \\
\text { Año 4. } 5,25 \% \\
\text { Año } 6.5,75 \% \\
\text { 7-30: } 6 \% \\
\text { semestralmente }\end{array}$ \\
\hline $\begin{array}{l}\text { Bonos a tasa flotante } \\
\text { (FRB o PDI-Floating } \\
\text { Rate Bonds/Past Due } \\
\text { interest) }\end{array}$ & 7.100 & $\begin{array}{l}12 \text { años, } \\
24 \text { cotas semestrales } \\
\text { Periodos } 1-5.0 \% \\
\text { Períodos } 6-12: 1 \% \\
\text { Periodo } 13: 5 \% \\
\text { Periodos: } 14-24: 8 \%\end{array}$ & $\begin{array}{l}\mathrm{LIBOR}+13 / 16 \% \\
\text { semestralmente }\end{array}$ \\
\hline
\end{tabular}

Fuente: Ambito Financiero, 07-04-93

Cuadro 28. Comercio exterior de mercancias argentino. (U\$\$1.000.000)

\begin{tabular}{r|r|r|r}
\hline Año & \multicolumn{1}{|c|}{ Exportaciones } & Importaciones & \multicolumn{1}{|c}{ Saldo } \\
\hline 1980 & 8.021 & 10541 & -2.520 \\
1981 & 9.143 & 9.430 & -287 \\
1982 & 7.624 & 5397 & 2.287 \\
1983 & 7.836 & 4.504 & 3.332 \\
1984 & 8.107 & 4585 & 3.522 \\
1985 & 8.396 & 3.814 & 4.582 \\
1986 & 6.852 & 4.724 & 2.128 \\
1987 & 6.360 & 5.818 & 542 \\
1988 & 9.135 & 5322 & 3813 \\
1989 & 9.579 & 4200 & 5379 \\
1990 & 12353 & 4.079 & 8.274 \\
1991 & 11.978 & 8275 & 3702 \\
1992 & 11.900 & 14.630 & -2.780 \\
\hline
\end{tabular}

Fuente: BCRA e INDEC (El Economista, Un año en la Argentina y el Mundo, edición 1993 - Ambito Financiero, para 1992).

Cuadro 29 - Estimaciones del balance de pagos. (U\$S 1.000.000)

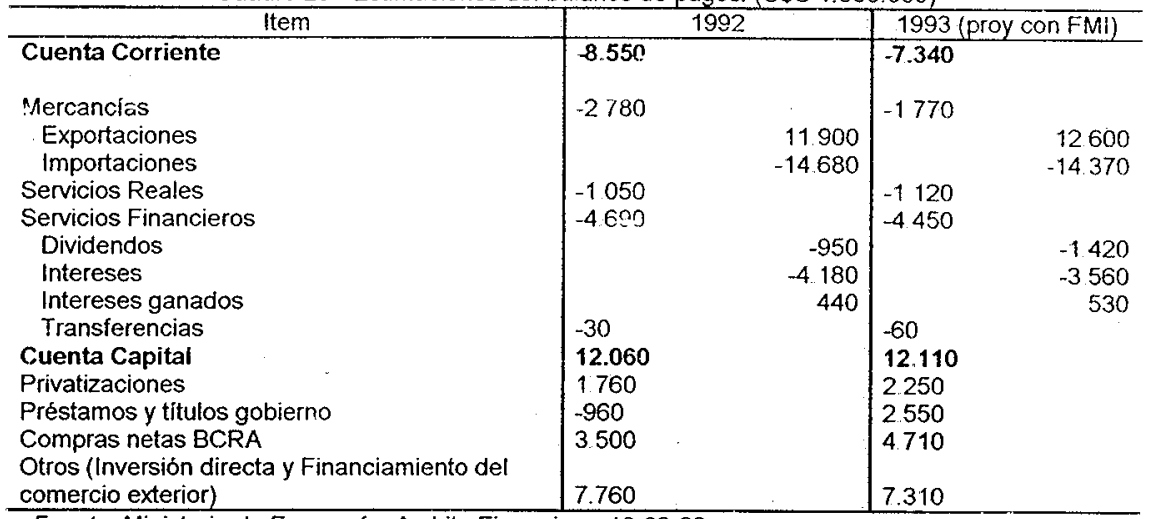

Fuente: Ministerio de Economia. Ambito Financiero, 18-03-93. 
Cuadro 30: Tipo de cambio real. Base 1986 $=100$

\begin{tabular}{l|r|r}
\hline \multicolumn{1}{|c|}{ Periodo } & \$1U\$S & \multicolumn{1}{|c}{ \$/cesta } \\
\hline Promedio 1986 & 100,0 & 100,0 \\
Promedio 1987 & 103,0 & 110,6 \\
Promedio 1988 & 98,3 & 109,5 \\
Promedio 1989 & 133,1 & 146,6 \\
Promedio 1990 & 90,1 & 107,1 \\
Promedio 1991 & 67,1 & 80,0 \\
abril 91 & 68,3 & 80,4 \\
Promedio 1991 & 62,5 & $77,04^{\mathrm{c}}$ \\
abril 92 & 63,2 & 76,0 \\
diciembre 92 & 61,2 & $76,2^{\mathrm{a}}$ \\
\hline
\end{tabular}

Fuente: BCRA (El Economista, Un año en la Argentina y el Mundo, ed 1993)

Notas: ${ }^{a}$ Deflactado por promedio de IPC e IPMAN contra IPC EEUU ' ${ }^{\circ}$ Idem a, dividida por canasta de 20 monedas poderadas por su participaciön en el comercio con Argentina. 11 primeros meses. ${ }^{\circ}$ nov

Cuadro 31: Estrucutura arancelaria

\begin{tabular}{|c|c|}
\hline Grupos de bienes & $\begin{array}{c}\text { Aranceles } \\
(\%)\end{array}$ \\
\hline $\begin{array}{l}\text { Estructura previa al } 28-10-92 \\
\text { - Bienes de capital no nroducidos en el pais } \\
\text { - Combustibles } \\
\text { - Materias primas, alimentos } \\
\text { - Alimentos más elaborados, productos intermedios } \\
\text { - Bienes de consumo final y de capital producidos en el pais } \\
\text { - Electrónicos de consumo } \\
\text { - Régimen especial para la industria automotriz con cupos aranceles } \\
\text { diferenciales para terminales localizadas en el país, empresas importadoras y } \\
\text { particulares } \\
\text { - Tasa de Estadística (todas las posiciones) }\end{array}$ & $\begin{array}{c}0 \\
5 \\
13 \\
22 \\
35\end{array}$ \\
\hline $\begin{array}{l}\text { Estructura posterior al } 28-10-92 \\
\text { - Bienes de capital no producidos en el pais combustibles e medicamentos } \\
\text { - Materia primas vegetales, animales y minerales } \\
\text { - Industria de la alimentación, celulosa, papel, petroquimica, siderurugia, textil } \\
\text { (menos confecciones), según grado de eleboración } \\
\text { - Bienes de capital producidos en el pais, partes y piezas, tejidos, manufacturas } \\
\text { finales de papel, plástico, siderurgia y otros metales } \\
\text { - Bienes de consumo final } \\
\text { Régimen especial para la industria automotriz con cupos aranceles } \\
\text { diferenciales para terminales localizadas en el pais, empresas importadoras y } \\
\text { particulares } \\
\text { - Tasa de Estadística (menos bienes de capital no producidos en el pais) }\end{array}$ & $\begin{array}{c}0 \\
2,5 \\
5 / 7 \\
5 / 10 / 12,5 \\
15 \\
20\end{array}$ \\
\hline $\begin{array}{l}\text { Estructura posterior al 01-05-92 } \\
\text { - Bienes de capital combutibles e medicamentos } \\
\text { - Materia primas vegetales, animales y mineraies } \\
\text { - Industria de la alimentación, celulosa, papel, petroquimica, siderurugia, textil } \\
\text { (menos confecciones), según grado de elaboración } \\
\text { - Tejidos, manufacturas finales de papel, plástico, siderurgia y otros metales } \\
\text { - Bienes de consumo final } \\
\text { - Régimen especial para la industria automotriz con cupos aranceles } \\
\text { diferenciales para terminales localizadas en el pais, empresas importadoras y } \\
\text { particulares } \\
\text { - Tasa de Estadistica (menos bienes de capital no producidos en el pais) }\end{array}$ & $\begin{array}{c}0 \\
2,5 \\
5 / 7 \\
5 / 10 / 12,5 \\
15 \\
20\end{array}$ \\
\hline
\end{tabular}

Fuente: Ministerio de Economía (Citado en Ambito Financiero). 
Cuadro 32: Estructura de reintegros: antes y después del 28-10-92

\begin{tabular}{l|c}
\hline \multicolumn{1}{c|}{ Grupos de bienes } & $\begin{array}{c}\text { Reintegro } \\
\%\end{array}$ \\
\hline Estructura anterior al 28-10-92 & \\
- Materias primas vegetales, animales y minerales (en algunos casos & 0 \\
negativas - retenciones) & 3,3 \\
- Industria de la alimentación, pesca, carne, algunos aceites & 6,7 \\
- Siderurgia & 8,3 \\
- Petroquimica, algunos productos siderúrgicos y algunos bienes de & \\
consumo final & 10 \\
- Bienes de capital y algunos bienes de consumo final & \\
- Matructuras anterior al 28-10-92 & 2,5 \\
- Industria de la alimentación, celulosa, papel, petroquimica, siderurgia, & $5 / 7$, \\
textil (menos confecciones), según grado de elaboración & $5 / 10 / 12,5$ \\
- Bienes de capital producidos en el país, partes y piezas, tejidos, & \\
manufacturas finales de papel, plástico, siderurgia y otros metales & 15 \\
- Bienes de consumo final & 20 \\
(estructura simétrica a los aranceles de importación) & \\
\hline
\end{tabular}
Fuente: Ministerio de Economía (citado en Ambito Financiero).

Cuadro 33 - La inflación en Argentina. Variaciones porcentuales anuales 1984-1992

\begin{tabular}{r|r|r|r|rr}
\hline Año & \multicolumn{1}{|c|}{ IPC } & \multicolumn{1}{|c|}{ IPMNG } & \multicolumn{1}{c}{ IPMNA } & IPMAgro & \multicolumn{1}{c}{ IPC } \\
\hline 1984 & 688,0 & 624,0 & 624,4 & 604,9 & 596,3 \\
1985 & 385,4 & 363,9 & 363,9 & 336,4 & 279,8 \\
1986 & 81,9 & 57,8 & 55,8 & 73,7 & 80,8 \\
1987 & 174,8 & 181,8 & 182,8 & 153,5 & 174,3 \\
1988 & 387,7 & 431,6 & 430,3 & 455,3 & 116,3 \\
1989 & $4.923,3$ & $5.386,3$ & $5.289,7$ & $5.526,3$ & $6.052,3$ \\
1990 & 1343,9 & 798,4 & 846,8 & 659,8 & 779,6 \\
1991 & 84,0 & 56,7 & 55,1 & 62,0 & 75,1 \\
1992 & 17,5 & 3,0 & 2,0 & 9,5 & 25,8 \\
\hline
\end{tabular}

Fuente: INDEC. Ambito Financiero, 06-05-93. 
Cuadro 34 - La inflación en Argentina.

Variaciones porcentuales mensulaes (enero 1991-abril1993)

\begin{tabular}{c|c|c|c|c|c}
\hline Mes & IPC & IPMNG & IPMNA & IPMAgro & ICC \\
\hline ene 91 & 7,7 & 10,1 & 10,3 & 2,0 & 8,0 \\
feb 91 & 27,0 & 37,9 & 38,8 & 21,6 & 40,0 \\
mar 91 & 11,0 & 0,4 & 0,5 & 1,7 & 3,0 \\
abr 91 & 5,5 & 1,4 & 0,7 & 9,6 & 5,5 \\
may 91 & 2,8 & 1,0 & 0,1 & 10,2 & 1,1 \\
jün 91 & 3,1 & 1,1 & 0,6 & 7,0 & 2,2 \\
jul 91 & 2,6 & 0,4 & 0,1 & 3,1 & 0,1 \\
ago 91 & 1,3 & $-0,4$ & $-0,4$ & $-0,3$ & 1,1 \\
sep 91 & 1,8 & 0,4 & 0,2 & 1,9 & 0,5 \\
oct 91 & 1,4 & 0,7 & 0,6 & 0,8 & 0,4 \\
nov 91 & 0,4 & $-0,9$ & $-0,2$ & $-5,7$ & 0,5 \\
dic 91 & 0,6 & $-1,0$ & $-0,9$ & $-1,5$ & 0,7 \\
ene 92 & 3,0 & 0,4 & 0,1 & 3,3 & 1,1 \\
feb 92 & 2,2 & 0,3 & 0,0 & 3,6 & 1,2 \\
mar 92 & 2,1 & 1,4 & 1,3 & 2,9 & 2,1 \\
abr 92 & 1,3 & 0,2 & 0,5 & $-2,3$ & 2,5 \\
may 92 & 0,7 & 0,0 & 0,5 & 3,0 & 1,0 \\
jun 92 & 0,8 & 0,8 & 1,2 & $-1,2$ & 3,4 \\
jul 92 & 1,7 & 0,9 & 0,5 & 3,6 & 3,4 \\
ago 92 & 1,5 & 0,4 & 0,0 & 4,9 & 1,3 \\
sep 92 & 1,0 & 0,7 & 0,0 & 5,3 & $-0,2$ \\
oct 92 & 1,3 & 1,0 & 0,1 & 0,0 & 0,1 \\
nov 92 & 0,5 & $-1,8$ & $-1,3$ & $-7,2$ & 1,6 \\
dic 92 & 0,3 & $-0,6$ & $-0,7$ & $-0,9$ & 1,3 \\
ene 93 & 0,8 & 0,8 & 0,2 & 5,4 & 0,6 \\
feb 93 & 0,7 & 0,8 & 0,7 & 2,2 & 0,1 \\
mar 93 & 0,8 & $-0,6$ & 0,3 & $-0,2$ & 1,6 \\
abr 93 & 1,0 & 0,8 & 0,4 & 3,6 & 1,4 \\
\hline Fuente INDE & 1,0 & & &
\end{tabular}

Fuente: INDEC. Ambito Financiero, 06-05-93

Cuadro 35: Agregados monetarios, moneda doméstica expresados cn millones de U\$S

\begin{tabular}{c|r|r|r}
\hline Periodo & Base & M1 & \multicolumn{2}{c}{ M2 } \\
\hline ene 91 & 3.867 & 4.707 & 9.274 \\
feb 91 & 4.130 & 3.450 & 6.845 \\
mar 91 & 4.800 & 3.771 & 7.501 \\
abr 91 & 4.906 & 4.452 & 8.195 \\
may 91 & 6.498 & 4.938 & 8.810 \\
jun 91 & 6.616 & 5.316 & 9.214 \\
jul 91 & 6.014 & 5.836 & 9.672 \\
ago 91 & 6.140 & 5.936 & 10.119 \\
sep 91 & 6.443 & 6.136 & 10.471 \\
oct 91 & 6.727 & 6.503 & 11.106 \\
nov 91 & 7.221 & 6.804 & 11.660 \\
dic 91 & 7.665 & 7.893 & 12.857 \\
ene 92 & 7.993 & 8.419 & 13.533 \\
feb 92 & 8.300 & 8.216 & 13.519 \\
\hline
\end{tabular}


Cuadro 35: Agregados monetarios, moneda doméstica expresados en millones de U\$S

\begin{tabular}{c|r|r|r}
\hline Período & Base & M1 & \multicolumn{1}{c}{ (conclusão) } \\
\hline mar 92 & 8.028 & 8.494 & 14.179 \\
abr 92 & 8.551 & 8.820 & 14.596 \\
may 92 & 9.352 & 9.428 & 15.852 \\
jun 92 & 9.270 & 9.979 & 17.213 \\
jul 92 & 9.918 & 10.773 & 18.078 \\
ago 92 & 9.977 & 10.856 & 18.770 \\
sep 92 & 9.469 & 10.781 & 19.235 \\
oct 92 & 9.714 & 10.813 & 19.353 \\
nov 92 & 9.728 & 11.048 & 19.702 \\
dic 92 & 11.016 & 11.581 & 20.542 \\
ene 93 & 12.112 & 12.100 & 21.154 \\
feb 93 & 12.285 & 12.731 & 21.572 \\
mar 93 & 12.211 & 12.034 & 22.448 \\
abr 93 & 11.716 & 12.283 & 23.103 \\
\hline
\end{tabular}

Fuente: BCRA (El Economista, Un año en la Argentina y el Mundo, edición 1993 Ambito Financiero, varios numeros para 1993)

Nota: Base monetaria = Circulante + Reservas de los bancos

M1 = Circulante + Depósitos a la vista

M2 = M1 + Depósitos en Caja de Ahorro + Depósitos a Plazo Fijo

Cuadro 36 - Capacidad prestable del sistema financiero $(\$ 1=$ U $\$ S 1)$

\begin{tabular}{c|r|r|r}
\hline Periodo & Millones de $\$$ & Millones de U\$S & \multicolumn{1}{|c}{ Total } \\
\hline abr 1991 & 3.239 & 3.246 & 6.485 \\
abr 1992 & 6.411 & 7.135 & 13.546 \\
abr 1993 & 18.306 & 10.186 & 28.492 \\
\hline
\end{tabular}

Fuente: BCRA (El Economista, Una año en la Argentina y el Mundo, edición 1993 - Ambito Financiero para abril de 1993)

Cuadro 37 - Tasas de interes pasivas. Porcentaje mensual

\begin{tabular}{c|c|c|c}
\hline Periodo & Caja de Ahorro & Plazo Fijo & Call \\
\hline ene 91 & 0,13 & 1,15 & 1,44 \\
feb 91 & 0,65 & 0,91 & 0,79 \\
mar 91 & 0,61 & 0,90 & 0,91 \\
abr 91 & 0,60 & 0,93 & 1,11 \\
may 91 & 0,60 & 0,93 & 0,92 \\
jun 91 & 0,55 & 0,81 & 0,59 \\
jul 91 & 0,58 & 0,81 & 1,22 \\
ago 91 & 0,57 & 0,88 & 1,10 \\
sep 91 & 0,58 & 0,92 & 1,04 \\
oct 91 & 0,58 & 0,97 & 1,09 \\
nov 91 & 0,83 & 1,15 & 2,00 \\
dic 91 & 0,75 & 2,00 & 2,80 \\
ene 92 & 0,69 & 1,15 & 0,99 \\
feb 92 & 0,53 & 1,31 & 0,43 \\
mar 92 & 0,48 & 0,96 & 0,37 \\
\hline
\end{tabular}

Fuente: Ambito Financiero, 11-03-93. 
Cuadro 38: Depósitos totales en moneda extranjera. (U\$S 1.000.000)

\begin{tabular}{l|r|r|r}
\hline \multicolumn{1}{|c|}{ Mes } & 1991 & 1992 & 1993 \\
\hline Enero & $3.150,0$ & $6.970,6$ & 11341,0 \\
Febrero & $3.273,9$ & $7.445,9$ & $11.415,0$ \\
Marzo & $3.387,4$ & $7.899,2$ & $12.181,0$ \\
Abril & $3.741,4$ & $8.200,5$ & $12.733,0$ \\
Mayo & $4.284,3$ & $8.650,2$ & \\
Junio & $4.598,5$ & $9.057,5$ & \\
Julio & $4.481,6$ & $9.522,9$ & \\
Agosto & $5.211,2$ & $10.084,0$ & \\
Septiembre & $5.723,2$ & $10.453,0$ & \\
Octubre & $6.109,5$ & $10.705,6$ & \\
Noviembre & $6.363,5$ & $10.976,6$ & \\
Diciembre & $6.560,5$ & $10.983,3$ & \\
\hline
\end{tabular}

Fuente: BCRA (El Economista, Un año en la Argentina y el Mundo, edición 1993 - Ambito Financiero para

Cuadro 39 - Compras de dólares

del BCRA desde la convertibilidad. (U\$S1.000.000)

\begin{tabular}{l|r|r|r}
\hline \multicolumn{1}{c|}{ Mes } & 1991 & 1992 & 1903 \\
\hline Enero & & & 479 \\
Febrero & & 370 & -173 \\
Marzc & 167 & 148 & -377 \\
Abril & 548 & 724 & 317 \\
Mayo & 203 & 855 & \\
Junio & 287 & 398 & \\
Julio & 169 & 729 & \\
Agosto & 390 & 389 & \\
Septiembre & 355 & 345 & \\
Octubre & 561 & 386 & \\
Noviembre & 420 & -229 & \\
Diciembre & 3.108 & 1.508 & \\
\hline Total (9.762) & & 6.402 & \\
\hline
\end{tabular}

Fuente: BCRA (El Economista, Un año en la Argentina y el Mundo, edición 1993 - Aríbito Financiero para 1993)

Cuadro 40 - Respaldo en divicas de la base monetaria. Porcentajeitotal

\begin{tabular}{l|r|r|r}
\hline \multicolumn{1}{c|}{ Mes } & 1991 & 1992 & 1993 \\
\hline Enero & 160,0 & 115,0 & 108,0 \\
Febrero & 130,0 & 108,0 & 111,0 \\
Marzo & 110,0 & 118,0 & 123,0 \\
Abril & 112,0 & 118,0 & 103,0 \\
Mayo & 111,0 & 112,0 & \\
Junio & 114,0 & 112,0 & \\
Julio & 111,0 & 110,0 & \\
Agosto & 107,0 & 109,0 & \\
Septiembre & 113,0 & 120,0 & \\
Octubre & 108,0 & 120,0 & \\
Noviembre & 109,0 & 114,0 & \\
Diciembre & 119,0 & 113,5 & \\
\hline
\end{tabular}

Fuente: IEERAL sobre BCRA (El Economista, Un año en la Argentina y al Mundo, edición 1993. Ambito Financiero para1993) 
Cuadro 41 - Evolución de la bolsa y títulos de deuda pública.

\begin{tabular}{|c|c|c|c|c|}
\hline Periodo & $\begin{array}{c}\text { Indice Bolsa } \\
1989=100\end{array}$ & $\begin{array}{l}\text { Volumen operado } \\
\text { (U\$S } 1.000 .000)\end{array}$ & $\begin{array}{l}\text { Bonex } 89 \\
(100 \mathrm{VN})\end{array}$ & $\begin{array}{l}\text { GRA C/ int } \\
\text { (deuda } \\
\text { externa) }\end{array}$ \\
\hline 1991 & & & & \\
\hline Enero & 105,3 & 2,1 & 52,5 & 19,6 \\
\hline Febrero & $115 ; 0$ & 2,7 & 51,2 & 18,4 \\
\hline Marzo & 163,3 & 9,8 & 56,2 & 16,7 \\
\hline Abril & 210,3 & 11,8 & 64,9 & 20,2 \\
\hline Mayo & 234,3 & 11,6 & 67,6 & 23,1 \\
\hline Junio & 209,4 & 6,8 & 65,8 & 23,1 \\
\hline Julio & 214,3 & 5,0 & 64,9 & 27,4 \\
\hline Agosto & 330,3 & 39,3 & 74,9 & 33,3 \\
\hline Septiembre & 447,2 & 28,2 & 78,7 & 33,5 \\
\hline Octubre & 585,8 & 38,2 & 80,1 & 36,0 \\
\hline Noviembre & 546,8 & 28,3 & 79,6 & 34,0 \\
\hline $\begin{array}{l}\text { Diciembre } \\
199 ?\end{array}$ & 559,8 & 32,6 & 78,9 & 35,9 \\
\hline Enero & 643,2 & 22,0 & 77,1 & 38,3 \\
\hline Febrero & 675,3 & 43,2 & 77,7 & 38,9 \\
\hline Marzo & 657,3 & 44,0 & 79,8 & 40,6 \\
\hline Abril & 711,5 & 60,2 & 82,0 & 460 \\
\hline Mayo & 812,1 & 95,4 & 81,9 & 48,8 \\
\hline Junio & 763,0 & 101,8 & 82,5 & 50,7 \\
\hline Julio & 580,2 & 74,0 & 80,8 & 49,4 \\
\hline Agosto & 474,1 & 57,8 & 80,4 & 46,0 \\
\hline Septiembre & 447,1 & 56,6 & 81,2 & 46,6 \\
\hline Octubre & 339,2 & 58,4 & 80,4 & 43,7 \\
\hline Noviembre & 312,9 & 54,7 & 78,9 & 41,1 \\
\hline Diciembre & 378,9 & 64,8 & 79,9 & 43,8 \\
\hline
\end{tabular}

Fuente: Carta Económica (El Economista, Un año en la Argentina y el Mundo, edición 1993 - Ambito Financiero para 1993).

\section{APENDICE}

- Siglas de entidades y ürganismos meícionados en el texto

EERAL: Instituto de Estudios Económicos sobre la Realidad Argentina y Latinoamericana, Córdoba, privado.

FIEL: Fundación de Investigaciones Económicas Latinoamericanas, Buenos Aires, privada INDEC: Instituto Nacional de Estadistica v Censos, Buenos Aires, estatal

BCRA: Banco Central de la Repüblica Argentina

Ambito Financiero: diario especializado en economia, Buenos Aires.

El Cronista: diario especializado en economia, Buenos Aires.

El Economista: semanario especializado en economia, Buenos Aires

M\&S: consultora en economía, Buenos Aires.

Macroeconómica: consultora en economía, Buenos Aires

- Empresas del Estado

YPF: Yacimientos Petroliferos Fiscales

FFCC: Ferrocarriles Argentinos

ENTEL: Empresa Nacional de Telecomunicaciones.

TEAR: Telefónica de Argentina, licenciataria de la zona sur.

TELECOM: Telecom Argentina, licenciataria de la zona norte. 
SEGBA: Servicios Eléctricos del Gran Buenos Aires, sus licenciatarias son EDENOR y EDESUR. AyE: Agua y Energia, generación de electricidad.

SOMISA: Sociedad Mixta Siderúrgica Argentina. Actualmente Aceros Paraná

OSN: Obras Sanitarias de la Nación, agua potable

HIDRONOR: Hidroeléctrica Nor-Patagónica

ENCOTESA: Empresa Nacional de Correos

FEMESA: Ferrocarriles Metropolitanos.

JNG: Junta Nacional de Granos.

\section{B!BLIOGRAFIA}

AMBITO FINANCIERO. Varios números. Buenos Aires, 1991-93.

ARTANA, D. , LIBONATTI, O., RIVAS, C. Algunas consideraciones sobre el endeudamiento y la solvencia del sector público argentino. Boletín informativo Techint, Buenos Aires: Organización Techint, n. 266, 1991.

CASAS, Juan C Nuevas políticas y nuevos politicos en América Latina. Editorial Atlántida. Buenos Aires, 1991.

CAVALLO, D., DOMENECH, R., MUNDLAK, Y. La Argentina que pudo ser. Los costos de la represión económica. CINDE - Fundación Mediterránea - Manantial Buenos Aires, 1989

CONESA, Eduardo. La crisis del ' 93. Editorial Planeta Espejo de la Argentina Buenos Aires, 1992.

DI TELLA, Guido. Perón-Perón (1973-76) Editorial Sudamericana Buenos Aires, 1963

DOMENICONE, H. GUADIO, R., GUIBERT, A. Hacia un Estado moderno: el Programa cie Reforma Administrativa. Boletin Informativo Techint, Buenos Aires: Organización Techint, $n$ 269, enero-marzo, 1992.

EL ECONOMISTA. 1992 In año en Argentina y el Mundo. Edición 1993. Buenos Aires, febrero, 1993.

ESPEJO ORTEGA, Alberto. O plano de estabilização heterodoxo a experiência comparada de Argentina, Brasil e Peru. $13^{\circ}$ Prêmio BNDES de Economia. Rio de Janeiro, 1989

FIEL (Fundación de Investigaciones Económicas Latinoamericanas). Gasto y déficit cuasifiscal. Soletin Informativo Techint, Buenos Aires: Organización Techint, $\mathrm{n}$. 261, enero-febrero, 1990.

GRAZIANO, Walter Historia de dos hiperflaciones. Fundación Gabriel y Dario Ramos, 1991

LÜCKE, A y PASCUAL SPADA, T. La interdependencia del orden económico y político: dos experiencias latinoamericanas: Argentina (1976-81) y Chile (1973-83). ClEDDLA-Konrad Adenauer Stiftung. Buenos Aires 1986

LLACH, Juan José. Reconstrucción: o estancamierio. Premio Anual ADEBA Editorial Tesis. Buenos Aires, 1987.

RIBAS, Armando. Análisis histórico de los fracasos y repudiaciones de deudas. IT./C, Buenos Aires: ADEBA, Ext $/ 10$, marzo, 1991

ROJO, P. y CANOSA, A. El programa de desregulación del gobierno argentino Boletín Informativo Techint, Buenos Aires ' Organización Tochint, n. 269, enero-marzo, 1992.

\section{ABSTRACT}

\section{ADJUSTMENT AND STRUCTURAL REFORM IN ARGENTINE, 1989/93}

This work discusses the recent hyperinflation episodes in Argentine, emphasizing the macroeconomic policies adopted by different governments to fighting it. It also makes a retrospective description of economic policies in that country in the twentieth-century. Finaly, it makes a comment of the main economic measures and legislation rules that are connected with the convertibility Plan as well it shows some results up to 1993. 